\title{
Gender differences in airway behaviour over the human life span
}

\author{
Margaret R Becklake, Francine Kauffmann
}

Gender differences in airway behaviour and in the clinical manifestations of airway disease occur throughout the human life span and are related to biological as well as sociocultural factors. ${ }^{1-11}$ Though they have not escaped recognition, they have received less attention than gender differences in the rates of, for instance, cardiovascular disease, both in terms of research and their implications for clinical practice. $^{45^{10-12}}$ Physiologists have in general paid more attention than clinicians to gender differences in airway behaviour, even though gender differences are an important determinant of the clinical manifestations of airway disease. Similarly, in population based (epidemiological) studies of airway disease, gender is invariably considered a standardising variable rather than a determinant worthy of investigation in its own right. ${ }^{4}$ However, there have been some notable historical exceptions.

\section{Historical perspective}

In 1846 John Hutchison, ${ }^{1}$ a London surgeon, presented a report to the Royal Medical and Chirurgical Society entitled On the capacity of the lungs and the respiratory functions with a view of establishing a precise and easy method of detecting disease by the spirometer. He had developed the spirometer specifically for this research and his study is one of the first, if not the first, population based (epidemiological) study in respiratory health. One of the outcome measurements he used in his research was the "vital capacity" (VC), a term he coined to describe "the greatest voluntary expiration following the deepest inspiration". His study population comprised over 2000 men drawn from various professions and occupations (including soldiers, sailors, guardsmen, policemen, gentlemen, giants, and dwarfs) and 26 young girls, and he identified height, weight, and age as the important determinants of VC. His epitome (as he called his summary) does not include a comment on whether there were gender differences, probably wisely given the limited number of women in his study sample. He did, however, focus on gender differences in breathing movements, which he measured by tracing in profile "the shadows under a strong light, during different stages of respiration .. in upwards of 1500 cases", and he noted that "in men these are chiefly by the diaphragm; in women chiefly by the ribs" but that "extraordinary breathing" (by this he meant the VC) is the same in the two sexes. Though he could not, in his own words, "account for this", he did not believe it was due to "their peculiar costume" but speculated that "it might be a provision against those periods when the abdomen contains the gravid uterus".

Over 30 years later, in 1894, a book entitled Man and woman: a study of human secondary sexual characters was published by Havelock Ellis. ${ }^{3}$ After reviewing the definitions of "secondary sex characters" used by previous writers, none seemed appropriate for his research so he proposed the following classification: as primary those related to "the sex organs that may fairly be regarded as essential for reproduction"; as secondary "those by which we distinguish male from female" (he regarded the breast as "the chief of the secondary sexual characters or as occupying a borderland between primary and secondary characters"); and as tertiary other less obvious differences which he called "relative and only perceptible when we take averages into account" and he pointed out that of these there are many.

In his book, which is extensively referenced and covers a remarkably wide range of topics, Ellis discusses those pertinent to airways disease in three chapters. In a chapter on Metabolism he notes that "it is well recognised that the vital capacity is decidedly less in women than in men" even when height was taken into account (VC was on average between 350 and $500 \mathrm{ml}$ greater in men than in women of the same height). These differences he attributed in part to biological factors ("women have less need of air than men"), based on their lower production of carbonic acid, and in part to cultural factors ("the result of artificial constriction of dress"), referring to the corsets worn by women of the day. In the chapter on Metabolism, Ellis also discussed gender differences in susceptibility to the various treatments as well as to poisons, citing as evidence that men were more susceptible than women to the effects of alcohol (delirium tremens was virtually never seen in women) and to chloroform (most deaths under chloroform anaesthesia occurred in men often undergoing only minor surgery). On the other hand, women were noted to be more susceptible to the effects of opium, mercury, antimony and antipyrine, all of which were accepted medical treatments of the era. In a chapter on The Viscera Ellis noted that "in nearly every dimension 
man's larynx is larger, the entire male larynx being about one third larger than the female". Finally, in a chapter on the Functional Periodicity of Women Ellis enlarged on the physiological changes which accompany menstrual bleeding. These include increased pigmentation of the nipples and a change in the timbre of the voice and a lowering of its pitch, such that one specialist noted in a letter to him that "in all Continental engagements with female singers, provision is made for suspension of duty during the menstrual period, but this does not obtain in English contracts". Ellis then went on to report in detail the recent discoveries reported in 1890 by Professor Ott of St Petersburg at an International Congress of Obstetricians and Gynaecologists. ${ }^{2}$

Ott set out to measure the physiological or biological (as opposed to the psychological and emotional) processes which accompany menstrual bleeding. His study covered over 68 monthly cycles in about 60 women in good health followed for 1-3 months. Daily measurements were made of body temperature, muscular force, VC, respiratory muscle force, and the rapidity of tendon reflex action, not all measurements being carried out in all women. For instance, VC was measured daily using a Hutchinson spirometer on 19 women over 19 menstrual cycles. He then combined the four sets of measurements to give an index of what he called "the functional energy of the feminine organism" which he expressed on a scale of $0-100 \%$ and which he argued gave "a correct general view of the monthly physiological curve". His results showed that this index of "functional energy" increased to a maximum intensity from approximately $52 \%$ in the mid cycle to a climax of $75 \%$ which occurred three days before menstruation and then started to fall immediately before or with the onset of menstrual bleeding to a low 35\% during the period, before returning again to the mid cycle level. In the face of what he describes as numerous research studies documenting the absence of cyclic monthly fluctuations in prepubertal girls and postmenopausal women, not only of temperature (which Ott had recorded in his studies) but also of other physiological parameters such as blood pressure and heart rate (which he did not measure), he felt justified in attributing the cyclical variation in his index of "functional energy" to factors related to the female organs of reproduction during the reproductive period of a woman's life. Though the daily measurements of VC were not displayed or reported separately in Ott's study, apparently they followed the curve of the other components of his "functional energy index". (Hutchinson reported a coefficient of variation for VC of the order of 3\% in adult men, well below the variation of $35 \%$ implicit in Ott's "functional energy index".)

A century later it is not inappropriate to review what has subsequently been added to our knowledge of the determinants of gender differences in airway behaviour, to ask the question whether the lungs in fact exhibit secondary and/or tertiary sexual characteristics as Have- lock Ellis suggested and, if so, to consider the clinical, public health, and research implications.

Definitions and objectives of this review

In this review we use the following definitions:

(1) Airway behaviour: a term to describe the dimensions, structure, and function of the airways and their relationship to each other and to the lung's mechanical properties.

(2) Determinant(s): this term will be used in the epidemiological sense to describe any factor-whether event, characteristic, or other definable entity - that brings about a change in the outcome under study, whether this is a health condition, or any other defined characteristic. ${ }^{13}$ Thus a determinant may be a cause or not, may increase or decrease risk, and can be established or putative (suspected).${ }^{14}$ In previous analyses ${ }^{45}$ we found it useful to distinguish between biological determinants implicit in the word "sex" (in other words, determinants related to the organs necessary for reproduction) and sociocultural determinants implicit in the word "gender" (a broader term which includes sociocultural and environmental as well as biological determinants of airway behaviour). We maintain the same distinction for the present review.

(3) Sexual characteristics: the term biological determinants is used to refer to what Ellis called the "primary sex characters" and sociocultural determinants to refer to what Ellis termed the "secondary and tertiary characters".

The objectives of this review are (1) to draw attention to what is known about gender differences in airway behaviour over the human life span; (2) to review the evidence on the determinants of these gender differences; (3) to offer a synthesis of how these interact to produce gender differences in the clinical manifestations of obstructive airway disease; and (4) to consider their implications for clinical and public health practice as well as for research. While excellent population based studies have been carried out focusing on age specific age/time windows, no study has been found covering the human life span from infancy to old age using comparable methodology (nor, indeed, is any such study likely or even possible). Our overview of gender differences in airway behaviour over the human life span has therefore been developed by assembling the findings from different studies, for the most part carried out by different investigators, often using different methodology, in different populations in different countries. Such methodological differences are, however, less likely to bias within study estimates of gender differences, the focus of our interest, than between study comparisons even of the same age groups.

\section{Biological determinants of sex differences in airway behaviour}

Throughout the human life span female lungs tend to be smaller and to weigh less at necropsy than male lungs. ${ }^{15}$ In older subjects they are less likely to be pigmented by carbon than male lungs, but they are otherwise indistinguishable to the pathologist on macroscopic as well as on microscopic examination. However, there are 
distinguishing morphometric, physiological, and behavioural characteristics evident even in utero and these can conveniently be grouped into the following categories ${ }^{45}$ : (1) dimensional determinants which have been characterised by morphometric and physiological studies including studies of structure/function relationships and which in general favour female lungs; (2) immunological determinants which are of particular importance in the context of conditions such as asthma which are characterised by variability in airway behaviour both in the short and long term, and (3) hormonal determinants which relate to the cyclical changes which take place throughout the reproductive phase of a woman's life. All contribute to the sex differences in airway behaviour which occur across the human life span but in different ways and in different proportions in different age/time windows, so each will be considered separately.

\section{Dimensional determinants of airway behaviour and structure/function relationships}

The structure of the lungs is an important determinant of their ventilatory function; this, in turn, is related to their mechanical properties and is reflected in the relationships of volume, flow, and time during a forced expiratory manoeuvre. The relationship of the forced expiratory flow rates at a given lung volume (a measure sensitive to airway size) to lung volume (a measure sensitive to lung size $)^{16-18}$ is also a measure of this structure/function relationship. This is because the static lung elastic recoil at any given lung volume is also the driving pressure behind flow during the effort independent part of the flow-volume curve when resistance has moved upstream and the equal pressure point ("choke" point) has moved out to the small airways ${ }^{17-19}$ - that is, during most of the forced expiratory manoeuvre. Even though the lungs of girls and women are smaller than those of boys and men of the same height, they exhibit higher forced expiratory flow rates (standardising for differences in body size), and the ratios of forced expiratory volume in one second $\left(\mathrm{FEV}_{1}\right)$ to forced vital capacity (FVC) ratios - that is, "the emptying rate of the lungs amortised over one second" $"$ - are higher in girls and women than in boys and men. ${ }^{90-23}$ These gender differences have been addressed within the concept of dysanapsis. ${ }^{17-19}$

\section{CONCEPT OF DYSANAPSIS}

To explain the marked variability of maximal expiratory flow rates between individuals with lungs of comparable volume, the term dysanapsis was proposed to describe what appeared to be this loose coupling between airway and lung size. ${ }^{17}$ This was attributed to disproportionate growth between the airways, whose number is fixed at birth and whose development appears to be complete by the 16 th week of gestation, and the air spaces which continue to multiply rapidly well into the early postnatal period and more slowly at least up to the age of two years and possibly longer. Thereafter the increase in lung volume occurs mainly from enlargement of the existing air spaces. Mead, who was responsible for the concept of dysanapsis, concluded from an analysis of the relationship of lung size to airway size in 21 men that it was airway length not diameter that determines the effort independent forced expiratory flow rates. $\mathrm{He}$ reasoned that "large lungs were penalised in two ways with respect to their airways because they operate with gas drainage systems that are, relatively speaking, both longer and narrower than those of small lungs". ${ }^{17}$ In addition, he compared the results from these 21 men with those of seven women and five boys and was surprised to find that, in the women, for the same lung volume the index of dysanapsis that he had used $\left(\mathrm{Vmax}_{50} / \mathrm{VC} \times \max \mathrm{P}(\mathrm{st}) \mathrm{L}\right.$ where $\mathrm{V} \max =$ maximum flow rate at $50 \%$ lung volume and $\mathrm{P}$ (static) $\mathrm{L}=$ maximum transpulmonary pressure $)^{17}$ was half that in the men, and that the values in the five boys were similar to those in the seven women. From this and theoretical calculations based on fluid dynamics he concluded that "the airways of men were approximately $17 \%$ larger in diameter than the airways of women", and speculated that "the adult sex difference in airway size develops relatively late in the growth phase".

Dysanaptic growth has been the focus of investigation in several other studies using morphometric $^{1524}$ and physiological techniques ${ }^{25-29}$ as well as epidemiological ${ }^{29-33}$ and clinical approaches, ${ }^{34}{ }^{35}$ in particular by paediatricians to whom changes in growth patterns are an ever present clinical issue. Since investigation of sex effects involves comparing lungs of different sizes, a major issue has been how to compare the function of lungs of different sizes - that is, how to "standardise" for size differences. In other words, given the considerable within and between gender variation in growth rates and in the patterns of growth, ${ }^{152432} 3637$ should lung or somatic size be the reference? The data underlying the answers to some of these issues are summarised in tables $1^{15242732}$ and $2 .^{15}$ 24-27 29-31 38-43 Although only human data are cited, they are backed by a considerable body of experimental animal data well documented elsewhere. 815244144

PRENATAL, PERINATAL, AND POSTNATAL SEX DIFFERENCES IN LUNG GROWTH AND DEVELOPMENT

While there appear to be no prenatal sex differences in the relationship of lung to somatic growth, at birth the lungs of girls are on average smaller than those of boys and they may have fewer respiratory bronchioles. ${ }^{15}$ On the other hand, maturation appears to be more advanced in the female than in the male fetus as early as from about 16 to 26 weeks in terms of mouth movements ${ }^{34}$ which reflect fetal breathing (now thought to be a critical determinant of lung development ${ }^{45}$ ), and in the period from about 26 to about 36 weeks in terms of phospholipid profiles reflecting its surfactant production. ${ }^{44}{ }^{46}$ In addition, in the last four weeks of gestation, and possibly earlier, specific airway resistance (sRaw) is lower in female than in male fetuses, ${ }^{39}$ suggesting prenatal sex differences in growth patterns of airways in relation to air spaces. Female neonates also tend to have higher size 
Table 1 Prenatal, perinatal, and early postnatal sex differences in lung growth and development

\begin{tabular}{|c|c|c|c|}
\hline Age & $\begin{array}{l}\text { Development } \\
\text { period }\end{array}$ & Morphology and physiology & Sex differences in morphology, maturation, and physiology \\
\hline \multicolumn{4}{|l|}{ Prenatal* } \\
\hline $1-5$ weeks & Embryonic $^{33}$ & Morphology: Lung bud formation ${ }^{243}$ & \\
\hline 6 to $\sim 15$ weeks & Pseudoglandular ${ }^{33}$ & $\begin{array}{l}\text { Morphology: Differentiation of airways; airway branching } \\
\text { pattern complete by } 16 \text { weeks }{ }^{24} \text {; airways smooth muscle } \\
\text { appears in trachea and starts to contract spontaneously }{ }^{38} \\
\text { Ciliated goblet cells appear at } \sim 12 \text { weeks }^{15} 38\end{array}$ & \\
\hline 16 to $\sim 26$ weeks & Canalicular $^{33}$ & $\begin{array}{l}\text { Morphology: Vascularisation occurs: acini develop }{ }^{24} \text {; Clara } \\
\text { cells appear by } 26 \text { th week }{ }^{15} 2438 \text {; fetal respiration begins to } \\
\text { influence lung development }{ }^{4144}{ }^{45}\end{array}$ & $\begin{array}{l}\text { Morphology: No sex differences in relationship of lung } \\
\text { growth to somatic growth }{ }^{40} \\
\text { Maturation: Mouth movements in female more advanced } \\
\text { than male fetus }{ }^{34}\end{array}$ \\
\hline 26 to $\sim 36$ weeks & Saccular $^{33}$ & $\begin{array}{l}\text { Morphology: Alveoli first appear at } 30 \text { weeks and are } \\
\text { uniformly present at } 36 \text { weeks; air space wall thickness } \\
\text { declines rapidly after } 28 \text { weeks } 1538 \\
\text { Rapid increase in lung volume }{ }^{40}\end{array}$ & $\begin{array}{l}\text { Morphology: See above } e^{40} \\
\text { Maturation: See above: also female fetus approximately } \\
1.5 \text { weeks ahead of male in lung phospholipid profiles } \\
\text { which reflect surfactant production and maturation }{ }^{44} 46\end{array}$ \\
\hline \multicolumn{4}{|l|}{ Perinatal and postnatal } \\
\hline $36-40$ weeks & & $\begin{array}{l}\text { Morphology: Alveolar multiplication occurs }{ }^{24} \\
\text { As gestation advances bronchial smooth muscle } \\
\text { increases relative to size of airway }{ }^{38}\end{array}$ & $\begin{array}{l}\text { Morphology: See above under } 16 \text { to } \sim 26 \text { weeks } s^{40} \\
\text { Maturation: More advanced in female than male lungs: } \\
\text { see above under } 16 \text { to } \sim 26 \text { and } 26 \text { to } \sim 36 \text { weeks } \\
\text { Physiology: Female lungs have lower specific airway } \\
\text { resistance than male lungs }{ }^{39}\end{array}$ \\
\hline Birth to $\sim 1$ week & & $\begin{array}{l}\text { Morphology: Proportion of goblet to ciliated cells } \\
\text { increases }{ }^{38} \text { Rapid alveolar multiplication continues. }{ }^{33} \\
\text { Proportion of goblet to ciliated cells increases rapidly }{ }^{38} \\
\text { Physiology: Neonates have proportionately larger airways } \\
\text { relative to lung volume (FRC), }{ }^{27} \text { higher size corrected } \\
\text { forced expiratory flow rates }{ }^{40}{ }^{41}{ }^{43} \text { and lower specific } \\
\text { airway resistance than older infants }{ }^{39}\end{array}$ & $\begin{array}{l}\text { Morphology: Female lungs smaller than male lungs, may } \\
\text { have fewer respiratory bronchioles }{ }^{24} \\
\text { Maturation: More advanced in female than male } \\
\text { lungs, }{ }^{44}{ }^{46} \text { premature female lungs less at risk for } \mathrm{RDS}^{44} \\
\text { and transcient tachypnoea of the newborn }{ }^{47} \text { than male } \\
\text { lungs and more responsive to hormone accelerators of } \\
\text { surfactant production }{ }^{44} \\
\text { Physiology: As above under } 36-40 \text { weeks }^{39}\end{array}$ \\
\hline 1 to $\sim 52$ weeks & & $\begin{array}{l}\text { Morphology: Formation of single capillary network occurs } \\
\text { and alveolar multiplication continues, }{ }^{33} \text { growth more or } \\
\text { less linear with age at least up to age } 2^{24} \\
\text { Physiology: Airway resistance increases rapidly to adult } \\
\text { levels in the first year of life }{ }^{39}\end{array}$ & $\begin{array}{l}\text { Morphology: See above under birth to } 1 \text { week }^{1524} \\
\text { Maturation: Female lungs more responsive than male } \\
\text { lungs to hormones }{ }^{44} \\
\text { Physiology: See above under } 36-40 \text { weeks, }{ }^{39} \text { female } \\
\text { infants also have higher absolute as well as size corrected } \\
\text { forced expiratory flow rates than male infants }{ }^{40}\end{array}$ \\
\hline
\end{tabular}

Compiled from references 15, 24, 27, 33, 34, 38-41, 44-46.

$\star$ Prenatal age expressed as weeks after conception.

corrected flow rates and specific airway conductance (sGaw) than male neonates, suggesting that the ratio of their large to small airways is higher. ${ }^{43}$ To what extent these differences can be attributed to differences in the phospholipid profile and to the role of surfactant in maintaining small airway patency is a matter of speculation. Despite their smaller size, the lungs of female neonates are at lower risk than those of male neonates for developing both transient tachypnoea of the newborn ${ }^{47}$ and respiratory distress syndrome (RDS), ${ }^{44}$ and they are also more responsive to hormone accelerators of surfactant production, presumably because of their more mature lung phospholipid profiles. ${ }^{44} 46$

\section{SEX DIFFERENCES IN LUNG GROWTH AND}

DEVELOPMENT DURING CHILDHOOD, ADOLESCENCE AND EARLY ADULTHOOD

The sex differences in the maturation and physiological performance of the lungs documented in early childhood persist throughout childhood into adolescence and adulthood (table 2). However, their profile, extent, and nature vary with different age/height/ maturation windows and, since this is often not taken into account, it is not surprising that different studies have led to different conclusions. ${ }^{3343}$ Nevertheless, there is some overall coherence in the findings. Firstly, the sex differences in lung size shown in infancy (using body length as the reference) are present throughout childhood and adolescence and persist into adulthood (using height as the reference), even during the brief period in adolescence when, because of differences in the age of onset of the pubertal growth spurt, girls are on average taller than boys of the same age (from 11 to 13 years $^{43}$ ). Secondly, the sex differences in effort independent forced expiratory flow rates (higher in girls and women than in boys and men) are most in evidence in early childhood, decreasing towards adolescence when the percentage ratio of residual volume (RV) to total lung capacity (TLC) increases in girls but not in boys. ${ }^{43}$ As a result, forced expiratory flow rates, when standardised for size to FVC (and expressed as FVC per second), are higher in girls and young women than in boys and young men, but not when standardised to TLC (and expressed as TLC per second). ${ }^{43}$ Thirdly, although the adolescent growth spurt starts earlier in girls than in boys, it appears to be of comparable duration, approximately two years, and fusion of the epiphyses occurs earlier in girls than in boys and their span to height ratio is less throughout their adult life. ${ }^{48}$ Thus, in adolescent girls, age related increases in FVC plateau or cease when somatic growth (height vs age) ceases, in contrast to adolescent boys in whom VC continues to increase well into the mid 20s, though at a slower rate. This is also partly because the maximum respiratory pressures generated by adolescent girls are lower than those generated by adolescent boys at all lung volumes ${ }^{49}$ due to what has been called a "muscularity effect" in boys and attributed to the influence of male sex steroid hormones. Also pertinent is the increase in muscle bulk, especially of the shoulder girdle. Finally, sex differences in the relation of tracheal area (measured by acoustic reflection techniques) to lung volume and to forced expiratory flow rates 
Table 2 Sex differences in lung growth and development in childhood, adolescence, and early adulthood

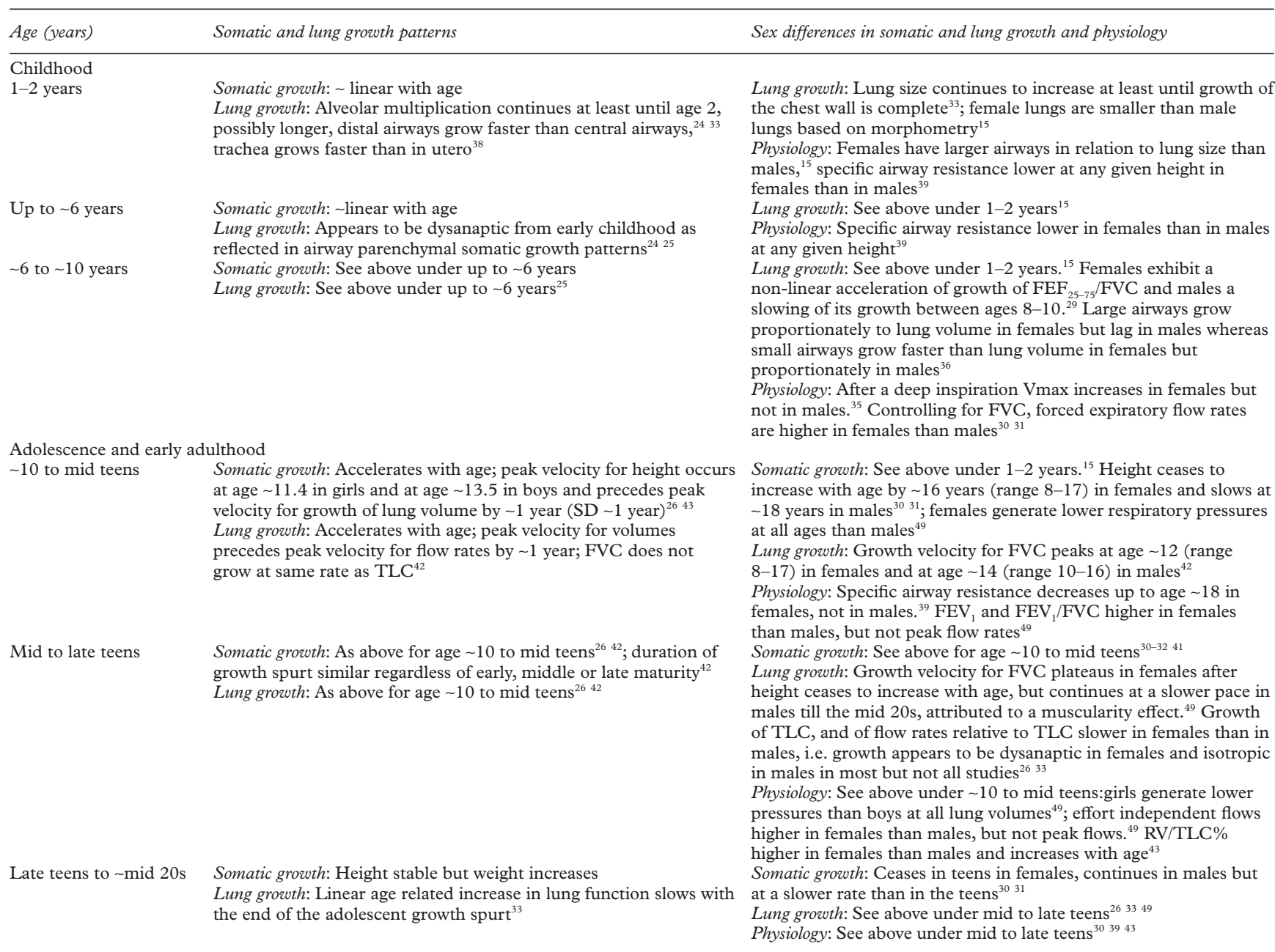

Compiled from references 15, 24-27, 29-31, 39-43.

$\mathrm{FEF}=$ forced expiratory flow rate; TLC $=$ total lung capacity; $\mathrm{FVC}=$ forced vital capacity; $\mathrm{FEV}_{1}=$ forced expiratory volume in one second.

in adults also support the concept that, in both men and women, the growth of the lung parenchyma and its airways occurs independently and that the configuration of the adult female lung is the result of proportional growth of its airways in relation to its parenchyma, but that of the adult male lung is the result of dysanaptic growth - that is, growth of the airways has lagged behind that of the lung parenchyma..$^{51}$ These dimensional advantages in female lungs are reflected in the reference (predicted) values for flow rates used routinely in the interpretation of pulmonary function tests carried out in clinical laboratories. An example is the $\mathrm{FEV}_{1} /$ FVC ratio for which prediction formulae derived from different populations, regions, and continents are all consistent in yielding higher values for girls and women than for boys and men. ${ }^{20-23} 41$

SEX DIFFERENCES IN LUNG STRUCTURE AND FUNCTION IN ADULTHOOD

From age 30 onwards - that is, after the age period covered in table 2 -age related changes occur in the morphometry of human lung reflecting a rearrangement of its internal anatomy. ${ }^{8}$ These include a decrease in the volume of alveolar air and increases in the volume of alveolar duct air and of lung connective tissue, changes associated with a decrease in lung elastic recoil and maximal expiratory flow rates, and airway closure at higher lung volumes. ${ }^{8}$ Changes related to ageing in the mechanical properties of the lungs develop later and proceed more slowly in women than in men. ${ }^{8}$ With increasing age the large airways of men also lose elastic recoil which may counteract the unfavourable effects of loss of parenchymal recoil and explain the relative preservation of their peak flow rates. ${ }^{51}$ No reports of comparable data have been found in women.

\section{Immunological determinants of airway behaviour}

Atopy is an important determinant of airway behaviour, a marker of immunological status, and an important - if not the most importanthost risk factor for asthma. ${ }^{52-54}$ The term atopy, which is derived from the Greek and means "out of place", was originally introduced in 1923 to describe a subgroup of clinical allergies which were subject to genetic influences and involved reaginic or skin sensitising antibodies. ${ }^{52}$ The term evolved in response to advancing knowledge of the underlying mechanisms. For instance, in 1975 Pepys proposed that it be used to describe that form of immunological activity of the subject in which "IgE antibody is readily produced in response to ordinary exposure to common allergens of the subject's 
environment." ${ }^{52}$ A current more compact definition describes atopy as "an adverse immune reaction involving IgE antibodies". ${ }^{53}$ In population based studies phenotype biomarkers which have been used to characterise atopy include skin prick reactivity to common allergens, total or specific serum immunoglobulin (IgE), blood eosinophil counts ${ }^{52-72}$ and, more recently in children up to two years of age, mononuclear cell proliferative and cytokine responses to specific allergens and tetanus toxoid..$^{73}$ These biomarkers differ in their evolution with age, their relationship to each other is complex, and not all studies have examined either for overall ${ }^{55} 566074$ or for age specific $^{56}$ sex differences. In reviewing published material (particularly epidemiological studies) for sex differences in the immunological determinants of airway behaviour, between study differences in methodology need to be taken into account. For instance, skin test reactivity has been variously defined as (1) a mean erythema of diameter $10.5 \mathrm{~mm}$ or more at the 20 minute reading ${ }^{56}$; (2) a mean weal diameter of $2 \mathrm{~mm}$ or more than the diameter of the control weal at the 20 minute reading; and (3) a quantitative index based on the sum of the diameters of all positive weals after subtracting the diameter of the control weal from each. ${ }^{5-58}$ All these definitions of atopy depend on the number of allergens included in the test battery which is usually made up of several indoor allergens (house dust mite, cat and dog dander) common to most studies as well as some locally important outdoor allergens (trees and/or grasses), usually different between studies. ${ }^{55-64}$

SEX DIFFERENCES IN ATOPY ASSESSED BY SKIN TEST REACTIVITY

In population based studies sex differences in atopy (assessed as skin test reactivity to one or more of a panel of allergens) have been reported throughout childhood and into early adulthood, with rates in girls and young women being lower than rates in boys and young men up to at least the age of 15 years and in most studies up to 25 years of age, ${ }^{59-61}$ but not consistently thereafter. ${ }^{57} 586263$ However, the relationship between atopy and sex is also complex and differs according to the age/sex/ gender windows examined. This is illustrated in the Tucson, Arizona studies in which a cohort of 1333 subjects aged 3 to $>75$ years at enrollment underwent allergy skin tests on two occasions at time intervals ranging from six to 10 years. $^{57}$ On the one hand, the acquisition rates of skin test positivity-that is, the increase in its prevalence between surveys - with age, which followed a similar pattern in girls and boys and in women and men, was greatest from childhood through the late teens and early 20 s when prevalence levels peaked. ${ }^{57}$ Thereafter acquisition rates tended to decline, quite rapidly until the 30 s after which the decline was slower but it accelerated again after the age of 50 years. $^{5758}$ Also, when averaged over the whole age range studied (6-74+ years), no sex differences in the prevalence of skin test positivity were reported in the first survey $(39.2 \%$ and $38.9 \%$ in women and men, respectively) or in the second survey $(50.3 \%$ and $51.2 \%$ in women and men). On the other hand, the rates in girls aged 5-14 years and in women aged 25-34, 35-44, and 45-54 years (that is, covering their reproductive years) were higher than those of boys and men of the same age groups at both surveys. The authors, in commenting on these age specific sex differences in prevalence rates of skin positivity, conclude correctly that, depending on the age and number of subjects in a study, an apparent sex effect may be noted, an effect which they considered spurious. ${ }^{57}$ However, despite the fact that the sex differences in age specific rates which their data show are in general agreement with published data, ${ }^{59-61} 75$ they nevertheless cite overall rates for age 3-75+ years (not age specific) in comparing their data with published material and conclude, this time incorrectly by their own reconnaissance, that "the (skin) reaction rate in men and women was virtually identical". 58

In addition to allergen exposure (including its frequency and intensity), the environmental determinants of skin test positivity include sibling status and smoking (active and passive). In the Tucson study acquisition and prevalence rates of skin reactivity rates were higher in nonsmokers and ex-smokers than in current smokers, an effect which the authors suggest may be due to atopic individuals not taking up smoking, comparable to the findings in occupational studies that those exposed to dusts at work have lower rates of skin test positivity than those not so exposed. ${ }^{65}$ In contrast to the Tucson study, skin reactivity rates were higher in smokers than in ex-smokers and non-smokers in a population based study carried out in 1905 subjects aged 8-73 years residing in the Po River Delta area in Italy. ${ }^{55}$ However, neither study provides information on interactions between gender and smoking interactions. ${ }^{57} 58$ In other studies which report no sex differences in skin test positivity, age specific comparisons do not appear to have been carried out. ${ }^{57}$

\section{SEX DIFFERENCES IN ATOPY ASSESSED BY TOTAL}

AND SPECIFIC SERUM IgE

In contrast to the sex differences in atopy assessed as skin test positivity which vary and change direction across the human life span, sex differences in atopy assessed as total serum IgE levels are consistent across the human life span, with levels in girls and women being lower than those in boys and men at all ages in most but not all studies. ${ }^{55-717374}$ Also, in contrast to atopy assessed as skin test positivity, the prevalence of which in the Tucson study, for instance, increased with age and remained at its highest levels, both in terms of prevalence and intensity of the skin reactions, in the 25-44 age group, atopy assessed by serum IgE levels was highest in childhood, declined quite rapidly towards age 25 years, then levelled off before declining again rapidly after the age of 45 years. ${ }^{57}{ }^{58}$ Sex differences in allergen specific (compared to total) IgE, however, were less consistent and appeared to depend on the prevalent antigens to which a community is exposed. For instance, in a population study of 
1512 adults aged 18-78 years resident in the Bergen area of Norway $^{71}$ the prevalence odds ratios (POR, 95\% confidence intervals) for six specific serum antibodies adjusted for age, subsample, smoking, and season of the year were only higher in men than women for house dust mite (POR 2.9, 95\% CI 2.2 to 7.1 ) among the indoor allergens and not for cat (POR 2.0, $95 \%$ CI 0.6 to 6.9 ) or mould (POR 3.6, 95\% CI 0.3 to 3.0), nor for either of the outdoor allergens tested (birch (POR 1.0, 95\% CI 0.5 to 2.1 ) and timothy grass (POR $1.6,95 \% \mathrm{CI}$ 0.8 to 3.1$)$ ). A plausible explanation is that the earliest and most likely sensitising exposure(s) to an indoor allergen such as house dust mite is likely to have taken place in early childhood when boys are more at risk for skin sensitisation than girls. ${ }^{58}$

In addition to allergen exposure, other environmental determinants of total serum IgE levels which have been identified include smoking (active and passive), occupational exposure, urbanisation, and migration..$^{57} 58676870$ Gender interactions with environmental factors which have only been examined in some studies are obviously complex. ${ }^{67}$ For instance, in a UK population based study of 882 adults aged 20-44 years, the only sex differences in an allergen specific IgE level (three were tested) was for an outdoor allergen, grass, which was lower in women than in men. ${ }^{67}$ In addition, in the same study total IgE was higher in men than in women, but only $1 \%$ of its variability was explained by smoking. Smoking was, however, associated with an increased risk of sensitisation to house dust mite but a decreased risk of sensitisation to grass and cat, another illustration of the complexity of these relationships. These and other similar results have led these authors to suggest abandoning the use of the definition of "atopic" as "the presence of specific IgE to one or more allergens" in epidemiological research addressing aetiological associations. They point out that use of this definition may mask associations of specific allergens with proposed risk factors with misleading results, particularly when atopy is being considered as a confounder or as an explanatory variable. ${ }^{67}$ The mechanisms underlying the interacting between smoking and IgE remain to be explained. ${ }^{70}$

IMMUNE STATUS (FETAL AND MATERNAL) DURING PREGNANCY AND THE IMPORTANCE OF EARLY LIFE EVENTS

Pregnancy involves two physiologies, that of the fetus and that of the mother. The placenta is a barrier to most blood constituents and yet fetus and mother are in close immunological proximity and transfer of IgG from mother to fetus is a natural feature of pregnancy. During pregnancy there also appears to be a bidirectional interaction between the maternal immune and reproductive systems, with the maternal immune system either enhancing or inhibiting the development of the fetoplacental unit, and the feto-placental unit redirecting maternal immunity away from cell mediated and towards enhanced humoral responsiveness. $^{76}$ The immune environment of the fetus is thus skewed toward the Th2 type of immune response due to cytokines produced by the amnion and placenta, and spontaneous abortion is likely to occur if this immune profile does not develop in time. ${ }^{54476} \mathrm{~T}$ cells from the cord blood of babies born to atopic mothers have also been shown to respond to aeroallergens as well as food allergens to which the mother was exposed during pregnancy. ${ }^{54}$ 77-80 Many of the cytokines are under the control of oestrogen levels as they increase during pregnancy and multiple effects of oestrogen on the fetal/maternal immune systems have been shown. ${ }^{81}$ Whether the sex of the fetus affects any of these relationships does not appear to have been studied.

Prenatal, perinatal, and early life events appear to be crucial in programming the infant's immune system during this period when it hovers in the balance between the Th2 and Th1 response to exposure to common allergens - that is, between the development of atopy and the asthma phenotype or not. ${ }^{72} 7482$ In addition to a family history of allergic conditions, breast feeding, having older siblings, recurrent early childhood infections (respiratory and/or intestinal), and certain vaccinations and inoculations such as BCG have been associated with a reduction in the risk of developing childhood allergy and/or asthma in studies adjusted for age, subsample, smoking, and season of the year. ${ }^{54} 79$ 83-87 By contrast, urbanisation and/or migration, particularly if it involves adopting a "westernised" lifestyle, is associated with an increase in atopy and allergic conditions such as asthma. ${ }^{81}{ }^{88-90} \mathrm{Sex}$ and/or gender differences in these relationships do not appear to have been examined. Programming of the fetal immune system by the mother could also explain the greater effect of maternal versus paternal allergy on the later development of allergy and asthma in the child.$^{54}$ Only one study was encountered which commented on sex differences in the fetal immune programming by the mother. In a study of 777 newborn infants in Detroit an association between a maternal history of asthma and an elevated cord blood IgE was shown for newborn girls but not for boys. ${ }^{91}$

\section{Hormonal determinants of airway behaviour}

Despite the evidence cited by Ellis over 100 years ago to the effect that the airways of women exhibit secondary sexual characteristics, and despite the recognition of the role of progesterone in driving the hyperventilation of pregnancy by Hasselbach as early as $1912,{ }^{92}$ the role of hormonal factors in airway behaviour is still poorly understood. ${ }^{45}$ There is, however, compelling evidence that, throughout a woman's reproductive life, her airways are subject to the influence of the cyclical variations in sex hormones which occur in relation to circadian rhythms, in relation to menstrual cycles and the use of the oral contraceptive pill, in relation to pregnancy, and in relation to the menopause and postmenopausal hormone substitution therapy. ${ }^{4}$ At times the influence of these hormonal factors on the airway behaviour and ventilatory function of women appears to be 
favourable, at times not. Many of the studies which provide information on the hormonal determinants of airway behaviour have been conducted in women with mild to moderate asthma. However, the classic study of Ott reported in 1890 on healthy subjects, ${ }^{2}$ the early studies by physiologists ${ }^{92}$ and several recent studies have included non-asthmatic women as a reference group. Not all recent studies distinguish between natural cycles and cycles experienced by women on oral contraceptives.

CIRCADIAN AND MENSTRUAL FLUCTUATIONS AND ORAL CONTRACEPTIVE USE

Circadian variation occurs in airway responsiveness to challenge by histamine, acetylcholine, and house dust mite allergen, the airways of diurnally active individuals being least responsive around noon time and most responsive around midnight. These fluctuations may exceed $100 \% .^{93}$ There appear to be no major sex differences though the range of fluctuation for women may be slightly greater than that for men between 06.00 hours and 18.00 hours and slightly less between 18.00 hours and 03.00 hours. Cutaneous responses to histamine and specific allergens also show marked circadian and menstrual cycle variability. ${ }^{93}$

In non-asthmatic women the ventilatory requirements for a given work load (and for a given oxygen uptake) are increased in the order of $30 \%$ during the luteal phase compared with the follicular phase of the menstrual cycle, ${ }^{94}$ and running exercise has been shown to be associated with a significant rise in post exercise plasma cortisol concentrations in a study of 12 non-asthmatic subjects. ${ }^{95}$ In addition, in non-asthmatic women in the premenstrual or perimenstrual period spirometric measurements ${ }^{2}$ and the gas transfer factor may be reduced ${ }^{96}$ while the levels of peak expired nitric oxide (NO), a marker of the biological activity of the endothelium derived relaxing factor, has been documented as approximately half those seen at mid cycle. ${ }^{97}$ However, in most studies of airway responsiveness to methacholine over the menstrual cycle, the changes are small and are reported as insignificant. ${ }^{94}$ 98-101 Also, in non-asthmatic women and in a case report of an asthmatic woman, theophylline clearance has been shown to be significantly higher during the luteal phase than in the follicular phase of the cycle. ${ }^{102}$ In other studies of non-asthmatic women the lymphocyte $\beta_{2}$ adrenoceptor $\left(\beta_{2}-\mathrm{AR}\right)$ density and airway responsiveness to adenosomonophosphate (AMP) challenge have been shown to increase, and exogenous progesterone (not oestrogen) given during the follicular phase to upregulate $\beta_{2}$-AR density during the luteal phase compared with the follicular phase ${ }^{104} \mathrm{By}$ contrast, in studies of asthmatic women decreases in $\beta_{2}$-AR density have been reported in the luteal phase, and exogenous administration of progesterone (not oestrogen) given during the follicular phase paradoxically decreased $\beta_{2}$-AR density and cyclic AMP airway responsiveness. ${ }^{104}$ Finally, age may also play a part in determining hormonal effects on $\beta_{2}$ adrenergic responsiveness. In young women paradoxical downregulation of $\beta_{2}-\mathrm{AR}$ has been demonstrated. ${ }^{101}$ In perimenopausal and postmenopausal women attenuated luteal phase progesterone production $^{105-107}$ and possibly anovular cycles may be associated with concomitant loss of $\beta_{2}-\mathrm{AR}$ in the premenstrual or perimenstrual period and be a factor exacerbating premenstrual asthma in a susceptible subgroup of asthmatic women. ${ }^{107}$

Premenstrual aggravation of their asthma occurs in many asthmatic women (up to $40 \%$ in some studies $\left.{ }^{101}{ }^{105-109}\right)$ and can be severe and even life threatening ${ }^{110}$ with fatal cases often reported at the onset and the end of the reproductive period of their lives. ${ }^{105-107}$ In a US study of 182 asthmatic women emergency room visits for their asthma occurred more frequently during the premenstrual period than in the pre-ovulatory, peri-ovulatory, or postovulatory stages of the cycle. ${ }^{111}$ In another US study of 221 asthmatic women 29 (13\%) reported reproductive factors as a trigger of their asthma but, in contrast to the last study, emergency room visits were more frequent in the pre-ovulatory (follicular) phase than in the other phases of their cycles. ${ }^{112}$ In a case series of 57 asthmatic women other determinants of premenstrual asthma included dysmenorrhoea, asthma severity, and the presence and level of bronchial reactivity. ${ }^{108}$ In studies of women whose asthma symptoms are exacerbated premenstrually, airway responsiveness to methacholine has usually ${ }^{113-115}$ but not always ${ }^{101}$ been found to be increased - that is, provocative concentration causing a $20 \%$ fall in FEV $\left(\mathrm{PC}_{20}\right)$ reduced-in the mid luteal phase (around day 21) and $\mathrm{FEV}_{1}$ and peak flow rates are usually decreased by approximately $10 \%$ in the late luteal phase (around day 24). ${ }^{101} 109{ }^{114} \mathrm{In}$ two case series of 11 and 14 asthmatic women, respectively, premenstrual aggravation of their asthma symptoms was evident from reviewing their daily diary cards recording symptoms using visual analogue scales and/or peak flow measurements, even among those not previously aware of any cycle related changes. ${ }^{100} 109$ In one of these studies ${ }^{109}$ oestradiol administration was associated with improvement in asthma symptoms and dyspnoea index scores, but did not appear to be related to $\beta_{2}$ adrenergic receptor density. In addition, in asthmatic women hypercapnic chemosensitivity is increased during the luteal phase of the menstrual cycle ${ }^{116}$ and their adrenocortical response to the stress of exercise may also be impaired..$^{95}$ Asthmatic women on the oral combined contraceptive pill also exhibit attenuated cyclical changes in airway reactivity and in peak flow variability associated with suppression of the normal luteal phase rise in sex hormones seen in non-asthmatic women not on the combined oral contraceptive pill. ${ }^{115}$

Mechanisms underlying premenstrual aggravation of asthma symptoms are clearly complex and are still poorly understood. ${ }^{101} 117$ The observation that levels of exhaled nitric oxide increase during the luteal phase of the cycle of non-asthmatic women ${ }^{97}$ suggests that premenstrual asthma is associated with an increase in airway inflammation. ${ }^{117-119}$ Another mechanism 
proposed is the elimination of the cyclical changes in $\beta_{2}$ adrenoreceptor regulation seen in non-asthmatic women experiencing normal cycles, ${ }^{103} 119$ a hypothesis based on evidence that these cyclical changes can be controlled by oral contraceptives, ${ }^{115}$ by a gonadotrophin releasing hormone analogue $(\mathrm{GnRH}),{ }^{110}$ or by oestrogen which attenuates the premenstrual responsiveness to adenosine phosphate in asthmatic women whose condition is stable. ${ }^{119}$ Other mechanisms which could explain the exacerbations of asthma associated with a sudden fall in progesterone premenstrually and perimenstrually include a decrease in smooth muscle contractility, microvascular leak, alterations in immunosuppressive activity, and a possible bronchodilator effect of progesterone. ${ }^{101117}$ Current research into these and other mechanisms underlying premenstrual aggravation of asthmatic symptoms ${ }^{97} 109117119120$ will, it is hoped, furnish the information required to establish standard treatment guidelines and protocols. ${ }^{117}$

In a paper entitled "Is asthma an endocrine disease?" ${ }^{\prime 1}$ an interesting hypothesis is developed to the effect that the disturbance of oestrogen levels which follows discontinuation of oral contraceptives by the mother may be one of the factors contributing to the rising prevalence of childhood and adult asthma seen in the latter half of the 20th century in industrialised countries as they adopt the sociocultural changes which accompany what has been called a "westernised" lifestyle. In industrialising countries where asthma rates are also rising, ${ }^{121-124}$ other environmental factors associated with urbanisation are usually thought to be more important - for example, in Ethiopia exposure to pesticides has been implicated. ${ }^{124}$

\section{PREGNANCY}

Pregnancy is accompanied by changes in lung and chest wall mechanics, ${ }^{92} 125$ progressive increases in transfer factor which stabilise at approximately 26 weeks, ${ }^{125}$ and increased ventilation at rest and on effort attributed to increased progesterone levels..$^{92}$ Peak flow rates, however, appear to remain stable throughout pregnancy. ${ }^{126}$ During pregnancy asthma may remain unchanged, it may improve, or it may get worse in roughly similar proportions. ${ }^{127-132}$ For instance, in a US study of 330 asthmatic women prospectively managed with symptom diary cards, these proportions were $33 \%, 28 \%$, and $35 \%$, respectively. ${ }^{130}$ After 36 weeks most women experienced their asthma symptoms less frequently and they were less severe. In women whose asthma symptoms worsened during pregnancy, this usually occurred between 29 and 32 weeks. Similar findings were reported in a Finnish study of 198 asthmatic women followed through pregnancy using changes in asthma medication required for symptom control as the marker of severity, ${ }^{131}$ and in a Canadian case series of 20 asthmatic women of childbearing age, actively seeking pregnancy, in whom methacholine challenge was used as the marker of asthma severity. ${ }^{127}$ In another Finnish study of 504 pregnant asthmatic women acute attacks were more likely to occur between 17 and 24 weeks. ${ }^{131}$ In a case report of acute severe intractable asthma in the first trimester of pregnancy in a 19 year old woman, rapid improvement followed abortion. ${ }^{129}$

In none of the studies cited above was the sex of the fetus reported, nor apparently was its potential influence on the mother's asthmatic symptoms during pregnancy considered. However, in one study carried out in London in 34 pregnant asthmatic women studied by diary cards, ${ }^{132}$ there was a tendency for asthma symptoms to decrease during pregnancy among the mothers of male fetuses and to increase among mothers of female fetuses. ${ }^{132}$ Thus, eight women reported that their asthma had improved (in eight the fetus was male, in no case female); 12 reported that their asthma had got worse (in four the fetus was male, in eight female), and in the 14 in whom their asthma had remained unchanged during pregnancy the fetus was male in six and female in eight. ${ }^{132}$ Despite the recognition that the female sex hormones appear to play an important role in asthma, despite the differences between women in how pregnancy affects their asthma, and despite the fact that the masculinisation of the embryo occurs with conception and that during pregnancy there appears to be a bidirectional interaction between the maternal immune and reproductive systems with the fetal immune system redirecting maternal immunity towards enhanced "humoral" responsiveness, the interesting question of if and how the sex of the fetus affects the mother's asthma appears to have attracted little research interest.

MENOPAUSE AND HORMONE REPLACEMENT THERAPY

Postmenopausal women are less at risk for developing asthma than premenopausal women. For example, in the US Nurses' Health Study, a prospective investigation of major disease in a cohort of over 93000 women, the relative risk of developing asthma in postmenopausal versus premenopausal women was 0.65 (95\% CI 0.46 to 0.92 ), a trend partly reversed by hormone replacement therapy. ${ }^{133}$ In a case series of 15 postmenopausal women with mild to moderate asthma, hormone replacement therapy was associated with clinical worsening but also, paradoxically, with a decrease in the diurnal variation of $\mathrm{FEV}_{1}$ and $\mathrm{FEV}_{1} / \mathrm{FVC}$, an effect which the authors attributed to a direct effect on bronchomotor tone. ${ }^{134}$ Postmenopausal women are also at risk for developing osteoporosis including kyphoscoliosis which, because of the consequent mechanical disadvantages to ventilation, may impose an additional burden on their handling of any postmenopausal changes in airway behaviour. ${ }^{5}$

\section{Environmental and sociocultural determinants of airway behaviour and their interaction with biological determinants}

In contrast to gender differences in biological (dimensional, immunological and hormonal) determinants of airway behaviour which operate throughout the human life span (though 
with variable strength and sometimes with opposite effects at different ages), environmental exposures $^{45}$ 135-141 and sociocultural factors ${ }^{142-144}$ which affect airway behaviour are likely to be comparable between the genders at certain periods in life-for example, home exposures and socialisation in early childhood-and different for others-for example, work exposures and social pressures in young adulthood. ${ }^{4}$ In addition, the impact of both environmental and sociocultural factors on gender differences (or similarities) in airway behaviour is likely to vary between communities, cultures and countries, given the dependence of environmental factors on factors such as the level of urbanisation and industrialisation and of sociocultural factors on factors such as the acceptability of smoking among women and the extent to which they participate in the commercial, entertainment, athletic, and sporting life of the communities in which they live. ${ }^{5}$ There is also increasing evidence of interaction (with effect modification) of biological determinants with environmental and sociocultural factors in the clinical manifestations of airway disease, in particular in the perception, reporting, and interpretation of respiratory symptoms. ${ }^{4}$

\section{ENVIRONMENTAL EXPOSURES}

In industrialised countries exposures common to both genders include environmental exposure to tobacco smoke (ETS) or passive smoking and alcohol use (usually more and less frequently experienced by women than men, respectively). ${ }^{45}$ In the case of active smoking, not only may the rates differ between genders, but these differences may be changing as the rates of active smoking in adolescent girls and women rise and rates in adolescent boys and men fall. ${ }^{5}$ Other exposures common to both genders include diet and nutrition (for instance, in the home environment in childhood) whereas in adolescence and early adulthood diets may again diverge, only to converge again between spouses and partners in adulthood. ${ }^{45}$ Socioeconomic factors and environmental exposures to community and workplace air pollution, for instance, are likely to show similar trends.

Women are also more likely to influence the home environment than men-for example, in determining diet and nutrition - and in maintaining the home free of dust and other potential allergens. ${ }^{45} \mathrm{By}$ the same token, they are more likely than men to be exposed to solvents, home cleaning materials, and personal hygiene and beauty products. Women are also more likely to be exposed to potentially harmful pollution by nitrogen dioxide $\left(\mathrm{NO}_{2}\right)$ from gas cookers and pilot lights, as are young children in the home. ${ }^{137-139}{ }^{141}$ On the other hand, women are less likely than men to experience harmful exposures related to leisure or home improvement activities - for example, welding fumes, isocyanate use, wood dusts and wood glues - as well as to exposures incurred at work in blue collar jobs or heavy industry. ${ }^{140}$ There is also some evidence of lower levels of perception and reporting of these occupational exposures in women than in men. ${ }^{143}$

In addition to gender differences in exposures to environments potentially harmful to airway behaviour, there is increasing evidence of gender differences in the biological response - that is, in the susceptibility - to such exposures, for instance to tobacco smoke, irritants and allergens. ${ }^{45} 136{ }^{145-149}$ In the case of tobacco exposure, this may in part be methodological ${ }^{150}$ and in part implicit in the interaction between gender and smoking. There is also some evidence that in young women the target structure for tobacco effects is their pulmonary vasculature while in young men it is their airways. ${ }^{135}$ Other potential sources of bias and reasons for the underestimation of the effects in women are (1) selection bias due to the "healthy" smoker effect, the result of those whose airways are less able to sustain the habit remaining non-smokers ${ }^{151} ;(2)$ information bias due to the fact that, though reported smoking levels may be similar for men and women, the confounding effects of passive smoking, which are likely to be higher in women than in men, are not always taken into account in analysis ${ }^{4150}$; and (3) diagnostic bias due to the observation that symptoms of airway dysfunction (such as shortness of breath with wheezing) reported by women may attract a different diagnosis from the diagnosis attracted when the same symptoms are reported by men. ${ }^{5}{ }^{152}$ Also, inferences about gender differences in airway behaviour, derived from epidemiological studies, depend largely on the constitution of the non-smoking (reference) group and this, in turn, depends on the definition of "non-smoker" and the reasons (probably very different) why women do not smoke and why men do not smoke. ${ }^{147} 148$ For example, pressures to quit smoking because of participation in competitive or commercialised sports are likely to affect fewer young women than young men in communities exhibiting a "westernised" life style; in other communities pressures on women not to smoke may be for religious reasons.

The operation of these potential gender biases is also likely to affect study inferences differently, depending on the study outcome and study question. Again, in the case of tobacco exposure, if the study outcome is a lung function measurement or a measurement of airway responsiveness, then selection bias due to the "healthy" smoker effect is likely to diminish estimates of gender differences in the response to environmental exposures in early adulthood. If the study outcome is a symptom, then gender differences in the response to tobacco exposure are also likely to be underestimated due to the confounding effect of passive smoking, usually experienced by more women than men. If the study outcome is a reported diagnosis, and if the smoking habit is taken into account in reaching a diagnosis, then the resulting diagnostic bias is likely to lead to over reporting of asthma and under reporting of COPD in women than in men, underestimation rather than overestimation of the role of tobacco smoking in the genesis of asthma in 


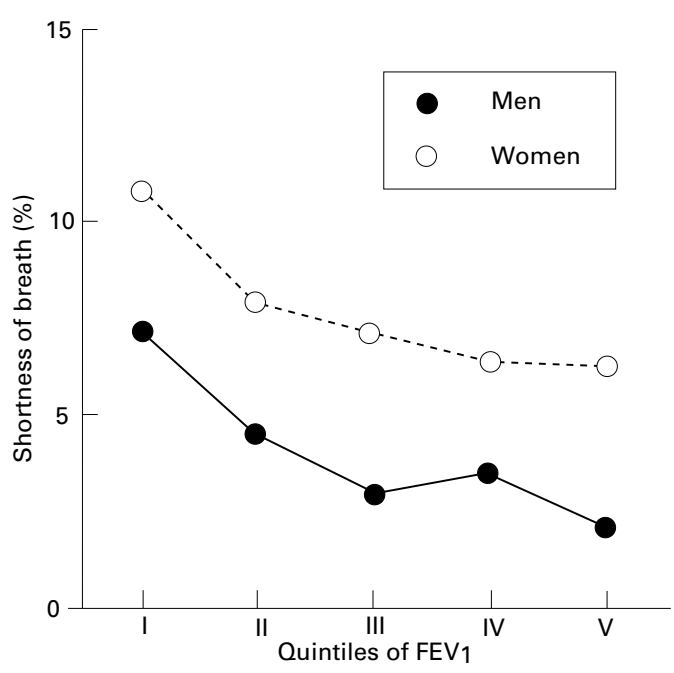

Figure 1 Gender differences in the relationship of reported shortness of breath to $F E V_{1}$. Prevalence (\%) of reported shortness of breath as a function of quintiles of $F E V$. Based on data gathered in the PAARC (Pollution Atmosphérique et Affections Respiratoires Chroniques) population based survey conducted in 1975 in seven French cities on approximately 20000 adults aged 25-59 years, excluding subjects with reported respiratory or cardiac disease. The quintiles of $F E V$, were defined separately for men and women, taking account of age. Reproduced from

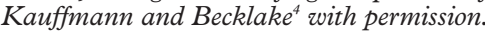

women, and overestimation rather than underestimation of its role in the genesis of emphysema in men. In other words, the operation of these various biases affecting gender comparisons may explain why the important question of whether there are gender differences in the susceptibility to tobacco exposure remains controversial. ${ }^{45}$

SOCIOCULTURAL FACTORS

Sociocultural factors are thought to play a role in the gender differences in the perception, reporting, and diagnostic interpretation of respiratory symptoms such as shortness of breath, cough, sputum production, and sleep disordered breathing (including snoring), all except shortness of breath being less commonly reported by women than by men. ${ }^{4}{ }^{153}$ Shortness of breath, a symptom associated with impaired ventilatory function and a clinical feature of COPD and emphysema, ${ }^{152}$ is consistently reported more frequently by women than by men in population based studies ${ }^{142}{ }^{154-157}$ even though mortality rates for COPD are consistently higher in men than in women over the age of 45 in most industrialised countries. ${ }^{158}$ Morbidity rates ${ }^{159}$ as well as rates for time off work show the same gender gradients. While gender differences in environmental exposures may have contributed to the gender gradients in reporting certain symptoms, they cannot explain the gender differences in the age standardised reporting rates for shortness of breath by level of FEV shown in fig 1 which is based on data from a study entitled "Pollution Atmosphérique et Affections Respiratoires Chroniques (PAARC)" carried out in seven cities across France and involving more than 20000 adults aged 25-59 years. ${ }^{460}{ }^{161}$ In that study, as fig 1 shows, though reporting rates for shortness of breath decreased with increasing levels of
$\mathrm{FEV}_{1}$ in a similar fashion in both men and women, at all levels of $\mathrm{FEV}_{1}$ reporting rates were higher in women than in men, differences for which the perception of shortness of breath may be responsible. These gender differences not only remained but increased after standardising for potential confounders such as smoking, occupational exposure, educational level, obesity, and $\mathrm{FEV}_{1}$ level. ${ }^{4}$

GENDER DIFFERENCES IN THE PERCEPTION, REPORTING AND INTERPRETATION OF RESPIRATORY SYMPTOMS

Interactions between biological determinants of airway behaviour (related to sex) and environmental and sociocultural determinants (related to gender) are complex as is their influence on how symptoms are perceived, reported, and interpreted by individual subjects and by their health care providers. ${ }^{45}$ On the one hand there is increasingly strong evidence of greater susceptibility of girls and women than boys and men to the effects of

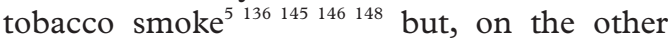
hand, there is also increasing evidence that what have been interpreted as sociocultural differences in the perception, reporting, interpretation (both by the individual and the health care provider) and in the management of symptoms of airway dysfunction and disease may have a biological basis. ${ }^{45}$

Gender differences in the perception of breathlessness is perhaps the most compelling example of the complexity of the interaction between environmental and sociocultural factors with biological factors. For instance, the perception of altered respiratory function by women may be more sensitive but less specific than by men as a result of their airway function being subject to cyclical hormonal variations (particularly of progesterone with its stimulating effects on minute ventilation) throughout their reproductive years. From this it follows that dyspnoea, a key element in quality of life scales ${ }^{162}$ may be perceived by women as a more global indicator of health than by men. Psychological factors such as depression have also been linked to the reporting of respiratory symptoms ${ }^{142}$ though gender differences in rates of reporting by psychological status do not appear to have been examined. In addition, in cultures in which prowess in competitive or commercialised sport is prized, it may be culturally more acceptable for a woman to report shortness of breath than for a man to do so.

By contrast, cultural factors appear to be more important in the lower rates of reporting sputum production among women than men. For instance, in the population based PAARC survey ${ }^{4}$ a question on "swallowed phlegm" was systematically asked in case of a negative answer to the question "do you usually bring up phlegm?" When increased mucus production was defined as answering "yes" to either question on phlegm, only $15 \%$ of men with mucus production reported swallowing phlegm compared with $41 \%$ of women. There may also be gender differences in cough reflex sensitivity 
which in turn might affect the perception of phlegm. ${ }^{163}$

There is also evidence of gender differences in the diagnostic interpretation placed by doctors on the symptoms associated with chronic airway disease. ${ }^{45}{ }^{152}$ In an analysis of 361 new cases of obstructive lung disease (asthma, emphysema, and bronchitis) recorded over eight years in the community based study carried out in Tucson, Arizona, a diagnosis of asthma was most often assigned to younger subjects, a diagnosis of emphysema to older subjects, and a diagnosis of chronic bronchitis more or less evenly assigned across all age groups. ${ }^{152}$ Also, in older subjects, all symptoms (wheeze, dyspnoea, and attacks of shortness of breath with wheeze) occurred frequently in association with all three diagnoses. However, most subjects who reported emphysema were men and most who reported asthma and chronic bronchitis were women, suggesting a gender bias in physician diagnosis. Finally, the male:female ratio for obstructive sleep apnoea, originally estimated as $8: 1$ on the basis of mainly clinical studies, has been shown to be of the order of 2:1 in population based studies, ${ }^{153}$ the difference being attributed to the reluctance of women to report or seek medical advice for snoring. There may also be a biological explanation for the lower reported rates of snoring in women related to the greater stability of their oropharynx and upper airways and attributed to the effects of female hormones (possibly progesterone) on genioglossus muscle activity. ${ }^{153}$

\section{Gender differences in the manifestations of obstructive airway disease over the human life span}

To what extent do the age related gender differences in airway behaviour described above provide an explanation for the gender differences in the clinical manifestations of airway disease which also change over the human life span? These have been documented in mortality statistics, ${ }^{4} 7158164$ morbidity data, ${ }^{164-168}$ and in population based epidemiological studies using various markers of airway disease, ${ }^{63} 64$ 169-174 and these are reviewed here to address the question posed.

The airway diseases in question and the criteria used to define and/or describe and/or diagnose for the present purposes ${ }^{175-184}$ are as follows. Asthma has commonly been defined using clinical criteria as "a condition characterised by airflow limitation which is spontaneously reversible or reversible on treatment"175; current definitions also describe asthma in terms of its underlying mechanisms as "a chronic inflammatory disorder of the airways in which many cells play a role. In susceptible individuals this inflammation causes symptoms (which) are usually associated with widespread but variable airflow limitation at least partly reversible either spontaneously or with a treatment. The inflammation causes an associated increase in airway responsiveness to a variety of stimuli". ${ }^{178}$ Chronic bronchitis is usually defined as chronic or recurrent bronchial hypersecretion and is described in terms of its main symptom, sputum production. ${ }^{175} 176$ Emphysema is usually described using anatomical or pathological criteria ${ }^{175}$ as "permanent enlargement of the air spaces distal to the terminal bronchioles accompanied by destruction of their walls and without obvious fibrosis"175 185 and, more recently, using imaging criteria. ${ }^{180}$ Chronic obstructive pulmonary disease (COPD) has been defined as a condition characterised by "the presence of chronic bronchitis or emphysema associated with airflow obstruction; the airflow obstruction may be accompanied by airway hyperactivity and may be partly reversible". ${ }^{175} 185$ In epidemiological studies COPD is commonly described in terms of its lung function deficit, either as a reduced $\mathrm{FEV}_{1}$ level (cross sectional studies) ${ }^{176} 184185$ or an accelerated rate of $\mathrm{FEV}_{1}$ decline (longitudinal studies). ${ }^{6176179}$

As with many other clinical syndromes there is considerable overlap between the clinical features of COPD and those of emphysema, chronic bronchitis, and asthma. ${ }^{152} 182185$ Nevertheless, the term COPD continues to be widely used by clinicians, perhaps because it permits the expression of uncertainty in an individual case as to the degree of reversibility of the airflow limitation and of the airway hyperresponsiveness, and perhaps to indicate their recognition of the diagnostic continuum embodied in what has come to be known as the Dutch hypothesis of the natural history of chronic non-specific lung disease. ${ }^{181}$ In addition, given that airway hyperresponsiveness is (1) considered a major marker of airway dysfunction in asthma, ${ }^{178} 182$ (2) may be a factor in the development of COPD, ${ }^{6179} 185$ and (3) together with wheeze within the last year is used to define clinically important current asthma for epidemiological studies, ${ }^{182}$ gender differences in the determinants of airway responsiveness will be considered separately.

AIRWAY RESPONSIVENESS

Airway responsiveness (AR) to non-specific challenges is cited as an example of the expression of the complex relationships between inherited genetic characteristics and exposure to the different environmental factors that determine airway behaviour. ${ }^{183}{ }^{186}$ Airway hyperresponsiveness (AHR) has been defined as "an abnormality of the airways which allows them to narrow too easily and too much, ${ }^{182}$ reflecting respectively the threshold at which the response to the challenge starts and the slope of the dose-response relationship of the response. The prevalences of AHR are greater than the prevalences of asthma symptoms and/or diagnosis in the same population. ${ }^{182} 187$ The absence of a generally accepted clinical definition of asthma has led to the suggestion that, for epidemiological studies, a useful definition and one compatible with a clinical diagnosis of asthma would be current wheeze and a $\mathrm{PD}_{20}$ $\left(\mathrm{FEV}_{1}\right)$ response to challenge with histamine or methacholine to a cumulative dose of $4 \mu \mathrm{mol}$ or less. ${ }^{182}$

Our analysis of the evolution of gender differences in AHR from infancy through childhood and adolescence into adulthood and 
aging also highlights the complex interactions of dimensional, immunological, and hormonal determinants of airway behaviour, depending on the age/gender windows examined. A major issue is thus to determine the extent to which differences across age/time windows are in fact due to technical differences in the execution of the test. ${ }^{182} 183$ 188-198 Technical differences include the choice of the provocation agent - for example, histamine, ${ }^{190} 193195$ methacholine, ${ }^{189} 1911^{192}{ }^{196-199}$ adenosine monophosphate ${ }^{115}$; how the agent is delivered-for instance, via a Mefar metered dose inhaler as in the ECRHS protocol, ${ }^{63}{ }^{197}$ delivery by a DeVillbis spray, ${ }^{193}$ a Wiesbaden Doppel inhaler device, ${ }^{195}$ a Wright nebuliser, ${ }^{191}$ or a compressed air device driving a nebuliser in infants ${ }^{188}$; and the inhalation procedure followed-for example, a single inspiration from functional residual capacity (FRC) to total lung capacity (TLC) with breath holding ${ }^{190} 193$ compared with several slow inspirations ${ }^{192}$ or tidal breathing. ${ }^{191}$ In addition, studies differ as to the procedure used to achieve a maximum forced expiration (in children and adults a voluntary coached effort ${ }^{190-192} 194195197198$ compared with a forced expiration achieved by sudden pressurisation of a plastic jacket surrounding the rib cage and abdomen in infants ${ }^{188}$ ); the fall in $\mathrm{FEV}_{1}$ used to define AHR (for example, $\mathrm{PD}_{15}$ in children ${ }^{193}$ and $\mathrm{PD}_{20}$ in adults ${ }^{190} 191193 \quad{ }^{197-199}$ ); and the maximum cumulative dose of the challenging agent administered (ranging, for instance, from $2.0 \mathrm{mg}^{193}$ to $\left.32.0 \mathrm{mg}\right){ }^{191}$ While bias due to these methodological differences will threaten between study comparisons, it is less likely to threaten within study comparisons of gender differences, for example, the thrust of our review.

An additional and perhaps even more important issue is how to standardise for differences in lung and airway size in comparisons across the various age/gender windows. ${ }^{188} 192200$ Thus, the increased airway responsiveness originally reported for infants compared with older children appears to be largely explained by less entrainment of air during the inhalation of the challenge, and hence the administration of a higher dose to the airways of the infants studied than to older children. ${ }^{188}$ Likewise, the comparisons of younger with older children are likely to be confounded by size (somatic, lung) and airway calibre, ${ }^{196}$ as are comparisons in adults within and between genders in which $\mathrm{FEV}_{1}, \mathrm{FEV}_{1} \%$ predicted, and $\mathrm{FEV}_{1} / \mathrm{FVC} \%$ have all been used to standardise for lung size and airway calibre. ${ }^{191} 192198$ For these reasons it is not surprising that findings (and their interpretation) differ between studies on the issue of gender differences and on their evolution over the human life span. Nevertheless, a certain coherence emerges when interpreted in light of what has already been said about gender differences in the dimensional, immunological and hormonal determinants of airway behaviour in relation to different age/gender windows.

In the neonatal period, size corrected flow rates are higher ${ }^{188} 196$ and sRaw is lower ${ }^{39}$ than in early childhood (table 1). In addition, in childhood the airway responses of girls to inhaled challenges to provoke (for example, methacholine) or to reduce (for example, atropine) airway tone are less than those of boys despite their smaller airway size. ${ }^{193}{ }^{196}$ Furthermore, in childhood the airways of girls respond to a deep breath by dilating whereas those of boys do not, a response which affects their larger and probably also their small airways since surfactant appears to play a part. ${ }^{33}$ In keeping with these findings is the observation that throughout childhood the prevalence of airway hyperresponsiveness is also less in girls than in boys. ${ }^{193}{ }^{196}$ By adolescence the level of airway responsiveness has decreased considerably in both girls and boys, although girls still retain the advantage of what appears to be a lower level of airway muscle tone despite forfeiting some dimensional advantages due to the greater growth of the large airways of boys in adolescence, even in studies not standardised for size. ${ }^{193}$ In studies of adolescents ${ }^{200}{ }^{201}$ gender differences will depend on the constitution of the study population(s) and the relative proportions of girls who have reached puberty (when endocrine factors are likely to have increased their airway responsiveness) and of boys (in whom muscularity effects ${ }^{49}$ are likely to have diminished their dimensional disadvantages compared with girls).

In adulthood there is less consistency in the gender differences in airway responsiveness reported, some of which may be due to differences in the age windows studied-for instance, if premenopausal and postmenopausal women are not separated in the analysis. Nevertheless, several (possibly most) studies, 192198199201202 including some not standardised for lung size, ${ }^{193}$ have found higher prevalence rates of airway hyperresponsiveness in women than in men; among the exceptions were studies in which crude prevalence rates were higher in women than in men but reversed after standardisation for airway size. ${ }^{191} 195$ Of particular interest is the observation that there are also gender differences in the determinants of airway hyperresponsiveness, tobacco exposure being implicated in women and atopy in men. ${ }^{192} 199{ }^{201}$ Overall, the evidence suggests that the airways of women show cyclical changes through their reproductive years during which they exhibit higher prevalence rates of airway hyperresponsiveness than men, suggesting that their airways are organs which exhibit secondary sexual characteristics. ${ }^{4}$ The mechanisms underlying gender differences in airway responsiveness are speculative. For instance, oestradiol is thought to affect the concentration of acetylcholine, the quality of mucus secretion, the production of prostaglandins, and the density of $\beta_{1}$ and $\beta_{2}$ adrenergic receptors in the lung. Many, though not all, gender differences in the factors influencing airway behaviour are also likely to be determinants of gender differences in airway hyperresponsiveness.

ASTHMA

Although there is evidence from the Tucson, Arizona birth cohort study ${ }^{203}$ that asthma 
originates soon after birth, its early natural history is not well understood. ${ }^{204}$ Thus, although wheezing with lower respiratory illnesses in the early years of life had occurred in almost half the 762 children followed in the study from birth to six years of age, those in whom persistent wheezing was present at the age of six years (and would therefore be likely to attract a clinical diagnosis of asthma) constituted only of the order of $28 \%$ of the study population. ${ }^{204}$ Male sex was also a significant risk factor for persistent wheezing at the age of six.

Although the clinical diagnosis of asthma is not usually made before the age of at least two years, from this age onwards through to old age gender differences in asthma rates have been observed, differences which are consistent across populations even though they change both in terms of degree and direction across the human life span. ${ }^{6364165167-174}$ These gender differences are elegantly illustrated in incidence data over the human life span from the large population based PAARC study referred to above (fig 2). ${ }^{160}$ The incidence rates for asthma shown in fig 2 by five year age periods were based on questionnaire information provided by study subjects on the age of onset of their asthma. Up to the age of five the incidence rates for asthma in girls were less than half those in boys, and can be reasonably explained by their more advantageous lung structure (reflected in lower indices of dysanapsis with higher expiratory flow rates at any given lung volume) and by their flow rates (and presumably also their airways) being more responsive to the relaxing effects of a deep breath which, in turn, is attributable to lower airway muscle tone and/or surfactant effects affecting small airway patency (table 2). Between the ages of five and 15, although incidence rates of asthma

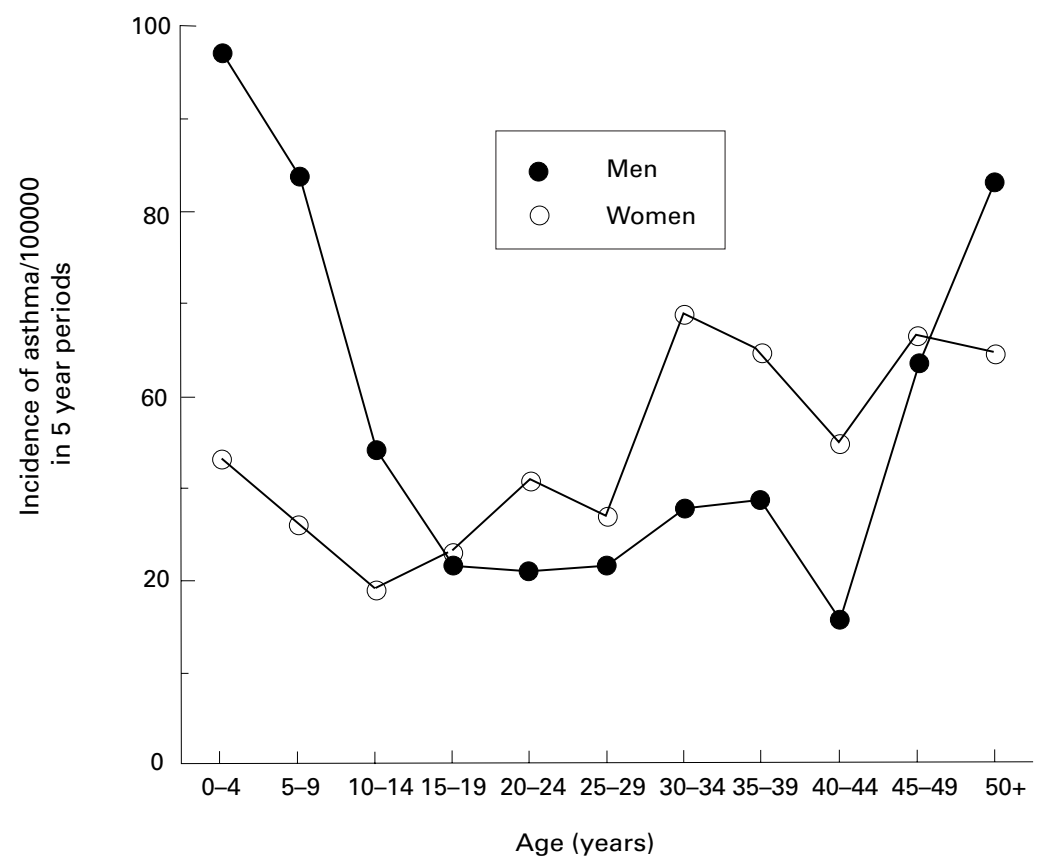

Figure 2 Sex and gender differences in airway disease across the human life span. Based on data gathered in the PAARC (Pollution Atmosphérique et Affections Respiratoires Chroniques) population based survey conducted in 1975 in seven French cities on approximately 20000 adults aged 25-59 years. Incidence was estimated retrospectively from reported age of onset of asthma. Reproduced from Kauffmann and Becklake ${ }^{4}$ with prom reported fell in both girls and boys, gender differences diminished because the incidence rates in girls fell less rapidly than those in boys, probably because the dysanaptic growth patterns seen in younger boys gave way to the more linear growth patterns seen in girls (table 2). As the girls reached puberty and moved into adolescence the incidence rates of asthma rose and, by the end of adolescence (age 15-19 in the PAARC study ${ }^{160}$ ), gender differences in the incidence of asthma were no longer demonstrable or were starting to reverse. During the reproductive period of women's life (15-49 years in the PAARC study ${ }^{160}$ ) asthma rates in women exceeded those of men despite the fact that women retain their more advantageous dimensional lung structure throughout life $\left(\mathrm{FEV}_{1} / \mathrm{FVC} \%\right.$ higher than that of men; table 2). Between the ages of 50 and 54 years (when, presumably, more women were menopausal) these rates were reversed. Other population based studies, ${ }^{164165}$ including those with a more limited age focus (for example, childhood ${ }^{170} 204$ adolescence, or adulthood ${ }^{159} 1711^{174}$ ), confirm the age trends shown in the PAARC study and are in general agreement with earlier reviews on gender differences in asthma. ${ }^{205}{ }^{206}$ In the reproductive period of a woman's life hormonal factors appear to be the dominant determinants of her airway behaviour and of its clinical consequences on, for instance, asthma rates. Late onset asthma is largely confined to women ${ }^{167}$ and usually starts around the menopause. In the US Nurses study ${ }^{167}$ postmenopausal hormone replacement therapy increased the subsequent risk of asthma and the risk increased with the duration of use of conjugate oestrogens, again providing evidence that the airways remain responsive to sex hormones even after the menopause.

CHRONIC OBSTRUCTIVE PULMONARY DISEASE Gender differences in mortality rates for COPD, of the order of $20-60 \%$ lower in women than in men, are reported for most industrialised countries ${ }^{4}$ and are consistent even though absolute ratios per 100000 differ considerably between countries. ${ }^{158}$ Once admitted to hospital for COPD, women are less likely to die than men. ${ }^{4}$ On the other hand, if they require mechanical ventilation their survival rates have been shown to be lower than those of men. ${ }^{173}$ In the USA during the period 1979-85 COPD mortality increased in men and women aged 55 years and over, but gender differences decreased due to the rise in death rates in women being faster than those in men. ${ }^{207}$ This was coincident with, and has been attributed to, an increase in tobacco use amongst women and a levelling off or fall in tobacco use by men. ${ }^{4}$ Similar mortality trends have been described in Canada. ${ }^{7}$ Morbidity from chronic airway disease in Canada also increased with age and exhibited the same gender gradients ${ }^{7}$ consistent with the US data. ${ }^{207}$ According to the Dutch hypothesis of its natural history, chronic airway disease is the consequence of the interaction of host factors in the form of two separately inherited genetic tendencies (to develop allergic reactions and to 
develop airway hyperresponsiveness), modulated by gender and age, interacting with environmental agents (allergens in the first instance, irritants in the second) and acting through a common pathway of airway inflammation. ${ }^{181}$ The phenotype expression can range from asthma through to chronic airflow limitation. It remains to be determined whether gender differences in the rates for COPD will equalise once women achieve a cumulative smoking exposure equal to that achieved by men over the past several decades.

Given the large numbers of subjects exposed to tobacco smoke, environmental exposure in the form of smoking must be considered a major determinant, if not the most important determinant, of COPD in terms of its public health impact. However, occupational exposures to dust and gases at work are now generally accepted as a cause of chronic airflow limitation (that is, COPD) and, for some exposures and in some communities, the ill effects appear to be comparable to those of tobacco use. ${ }^{208}$ In addition, in many countries, industrialised or industrialising, the number of women exposed at work is not trivial (up to $40 \%$ in some communities $^{209}$ ) with their estimated attributable risk being up to $20 \%$ in some studies of chronic bronchitis and up to $30 \%$ for some studies of COPD - that is, comparable to the estimates of attributable risk in men. ${ }^{209}$ The now quite strong evidence of an increased susceptibility of women to the effects of tobacco (see above under "Environmental exposures") is a strong incentive to pursue this line of investigation further and to address other environmental exposures in a similar fashion.

\section{Gender differences in airway behaviour across the human life span: clinical,} public health and research implications

The clinical implications of gender differences in lung size, structure, and function (see tables 1 and 2) have been incorporated into the clinical practice of respiratory medicine, paediatric and adult, in the form of gender specific reference (predicted) values used worldwide in clinical lung function laboratories. ${ }^{20-23} 210211$ The main function of these reference values is to take into account size and age differences which, for clinical purposes, are regarded as noise-that is, sources of variation not of interest-since the signal of interest in the clinical context is what is attributable to airway disease and/or dysfunction. ${ }^{211}$ Prediction formulae are derived from mathematical modelling of data, usually gathered in population based studies designed for other purposes. In these studies those who are symptomatic or exhibit other markers of disease are usually excluded and, in the case of adults, also those who smoke. The modelling underlying the data that has furnished most of the reference values for children, boys and girls alike, in the transition from childhood to adolescence is more complex than that underlying the changes which occur in adult life. This is not only because of the wide variations in the onset of puberty and in the peaks and duration of somatic and lung growth, but also because of the alinearity of somatic versus lung growth that accompanies puberty ${ }^{32}$ and the dynamic nature of human development itself. ${ }^{37}$ Nevertheless, a model which avoided the phase shift between the adolescent growth spurt in height and in lung volume proved remarkably robust when applied to data sets independently collected in five European countries, lending support to the feasibility of a single set of prediction equations for spirometric values (FVC, $\mathrm{FEV}_{1}$, and $\left.\mathrm{FEV}_{1} / \mathrm{FVC}\right){ }^{20}$ Most models function fairly well in the mid range of the characteristics of the populations which generated the data: for adults this is usually for age 30-50 years and for height $1.60-1.70 \mathrm{~m}$ for women and $1.65-1.80 \mathrm{~m}$ for men. This is because most models assume a linear relationship of lung function with age and height and, while this is approximately correct for the mid ranges, the linear model is likely to be incorrect at the extremes of age and height, the two determinants most usually included in the prediction formula. The consequences are usually an overestimation of the predicted lung function in the elderly and an underestimation in the young.

Other clinical implications devolve from the need to consider which determinants of airway behaviour (and of airway disease) predominate in the age/gender window of each patient under consideration and to focus the history accordingly. For instance, in women in their reproductive years enquiry into cyclical variation of symptoms, even if not already noticed by the patient, may bear on management as might knowledge of the gender of the fetus during pregnancy in an asthmatic subject. In a family in which one or both parents have a family history of asthma, male children may be more susceptible to environmental triggers than female children.

In terms of public health implications potentially most important is the evidence, still not strong but suggestive, that the airways of girls (and women) may be more sensitive to the effects of tobacco than those of boys and men. The question immediately arises as to whether this increased susceptibility is specific to tobacco smoke or is non-specific and therefore likely to apply to other environmental exposures, particularly work related exposures, a line of investigation important to pursue. In addition to supplying yet more evidence of the need to reduce the initiation of the smoking habit in adolescent girls and/or to diminish its intensity, these gender differences suggest that the materials and publicity used in these campaigns may need to be gender specific.

There are several research implications of which perhaps the most important is that, in descriptive and aetiological research, standardisation for gender should be replaced by stratification so that gender differences in occurrence, risk factors, and natural history (and, in the case of women, the relevant age/time window) can be studied. In clinical trials of drugs used to modify airway behaviour these should not only be analysed in a gender specific manner but, for women, information on their reproductive history and current 
status - that is, whether on oral contraceptives (premenopausal) or hormone replacement (postmenopausal) - should be taken into account in the evaluation of the treatment outcomes.

\section{Summary}

(1) Gender differences in airway behaviour occur throughout the human life span. Implicated in these differences are biological and sociocultural/environmental determinants related to sex and gender, respectively. Biological determinants of these gender differences in airway behaviour can be characterised as dimensional (related to structure/functional relationships), immunological, and hormonal.

(2) Dimensional determinants: gender differences in airway dimensions relative to lung size and in structure/function relationships exist throughout the human life span and are characterised by higher flow rates for a given lung volume in girls and women than in boys and men. These differences are present in utero, have been demonstrated as early as one month of life, and persist through childhood into adulthood. Before puberty boys start to reduce their dimensional disadvantage and, in adolescent girls, the growth of their airways relative to their size (and air spaces) is slower than in adolescent boys. Nevertheless, the lungs of girls retain their dimensional advantages over the lungs of boys and these persist throughout their adult life. Thus, even though women remain on average shorter than men throughout adulthood, and even though the lungs of adult women remain smaller than those of adult men, they exhibit on average higher flow rates in relation to their lung size than men.

(3) Immunological determinants of airway behaviour include atopy, probably the most important host determinant of airway behaviour. The phenotype biomarkers of atopy evolve differently with age. For instance, the acquisition of skin test positivity - that is, the increase in its prevalence rate with age-follows the same pattern in both sexes, being greater in childhood through early adulthood, but prevalence rates are lower in girls than in boys. Prevalence rates in both sexes coincide in the mid 20 s and stabilise at a lower level in the 30s, after which they both fall at an accelerated rate in the 50s. Also, although prevalence rates averaged over the human life span show no sex differences, in those studies where age specific rates have been examined, these are higher in women in their reproductive years than those of men of the same age, but lower in girls than boys in childhood and again in women than men after the menopause. By contrast, sex differences in total serum IgE levels are present across the human life span, with levels in girls and women being consistently below those in boys and men at all ages. The evolution of total serum IgE also differs from that of skin test posi- tivity, being highest in the first year of life, then decreasing rapidly to levels on average half those seen in childhood by the 30 s and 40 s and more slowly thereafter. Sex differences in allergen specific IgE are, however, less consistent. In one study of adults the only sex differences were for an outdoor allergen, grass, with lower levels in women than men. Gender differences in the determinants of the biomarkers of atopy other than allergen exposure (such as sibling and socioeconomic status, active and passive smoking, and occupational exposure) appear to have been less consistently examined. There is no evidence of gender differences in the relationship of skin positivity with sibling status. Higher and lower total serum IgE levels have been found in non-smokers than in smokers although gender differences do not appear to have been examined. The mechanisms of interaction between most environmental exposures and smoking remain to be explained.

(4) Hormonal determinants. Throughout the human life span female airways are responsive to their sex hormones and to their cyclical fluctuations, supporting the hypothesis formulated by Havelock Ellis over a century ago that their airways are among the organs which exhibit secondary sex characteristics. These fluctuations impose a pattern of variation on airway behaviour to which male airways are not subjected. In the fetus and the neonate, given their more mature surfactant production, female airways (particularly the small airways) have an advantage over those of the male neonate in terms of airway patency as well as relative size. In childhood the airways of girls are less responsive to non-specific challenges such as methacholine, an advantage in part due to their dimensional advantages. This difference diminishes progressively towards adolescence. As girls enter the reproductive period of their life and their airways become subject to the cyclical fluctuation of their sex hormones, they exhibit premenstrual changes which include increases in their airway responsiveness to methacholine, in their chemosensitivity, in their ventilatory demands especially on exercise, and decreases in their spirometric lung function and transfer factor. These cyclical fluctuations are modified by the use of oral contraceptives. During pregnancy there appears to be a bidirectional interaction between the maternal and fetal immune systems. For instance, $T$ cells in the cord blood of babies born to atopic mothers respond to aeroallergens as well as food allergens to which the mother was exposed during her pregnancy. Prenatal, perinatal and early life events also appear to be crucial in programming the fetal immune system as it hovers between the development or not of atopy and the asthma phenotype. During pregnancy the airways of the mother remain under the influence of her sex hormones, and there is also some evidence 
that the fetal sex hormones exert an influence on the mother's airway behaviour with her airways being less reactive if the fetus is male. After the menopause the level of airway reactivity decreases as does the risk of asthma, but this may reverse with hormone replacement therapy. Finally, despite the evidence that sex hormones influence many aspects of airway behaviour, the underlying physiological mechanisms remain poorly understood and the clinical implications poorly defined. Hormonal factors are probably the most important determinants of airway behaviour in women throughout their adult life and are probably the main determinants of the gender differences in the manifestations of chronic airway disease during their reproductive years.

(5) Environmental and sociocultural determinants. Gender differences in the environmental and sociocultural determinants of airway behaviour operate over the human life span but with varying strength and sometimes with opposite effects at different ages. In childhood environmental exposures are likely to be shared and are thus similar for girls and boys; in adolescence they are likely to be different but they probably converge again in adult life. Gender differences in the environmental determinants of airway behaviour may be partly biological - due, for instance, to different target structures for tobacco smoke (the pulmonary vasculature in girls and the airways in boys) - and/or partly because of gender differences in the environmental exposures experienced, and/or because of gender differences in the perception, reporting, and interpretation of the biological responses that these exposures evoke in, for instance, respiratory symptoms. For environmental exposures such as tobacco smoke, methodological differences-in part due to differences in the construction of the non-smoking reference group-may have contributed to an underestimation (until relatively recently) of the greater susceptibility of women compared with men to its ill health consequences. Sociocultural determinants clearly play a role in gender differences in the perception, reporting, and diagnostic interpretation placed on respiratory symptoms; for instance, acknowledging shortness of breath appears to be culturally more acceptable in women and acknowledging sputum production and sleep disordered breathing, including snoring, in men. In addition, for a given $\mathrm{FEV}_{1}$ deficit, rates of reporting breathlessness are consistently higher among women than among men in population based studies, evidence of biological differences in the perception of breathlessness by women compared with men. Reasons for this are speculative; for instance, the perception of breathlessness by women may be sensitised by the fact that their airways are subject and respon- sive to the hormonal fluctuations that occur throughout their reproductive life.

\section{Conclusions}

Airway behaviour is subject to the influence of sex related (biological) as well as gender related (sociocultural) determinants across the human life span. Awareness of these relationships provides a framework within which to interpret the gender differences in the clinical manifestations of airway disease which also occur across the human life span. Generalisations about gender effects are not only inappropriate but may also be misleading if derived from studies confined to limited age/time windows. Awareness of these gender differences in airway behaviour and in the manifestations of airway disease is important for clinical and public health practice as well as for research, whether descriptive, aetiological, or evaluative. In all these domains, rather than "standardising" for sex, the differential influence of sex and gender on airway behaviour should always be taken into account and the consequences of these gender differences in airway behaviour on the occurrence of airway diseases, acute and chronic, should be the target of investigation.

The authors wish to thank Dr David V Morris for his comments on the section on hormonal determinants, Dr Bruce Mazer for his comments on the section on immunological determinants, and Ms Danielle Bastien for her help in the preparation of the text.

1 Hutchinson J. On the capacity of the lungs and on the respiratory function with a view of establishing a precise and ratory function with a view of establishing a precise and Clin Trans $1846 ; 29: 137-252$.

2 Ott O. Les lois de la périodicité de la fonction physiologique dans l'organisme féminin. Nouvelles archives d'obstétrique et de gynécologie 1890;502-6.

3 Ellis H. Man and woman: a study of human secondary sexual characters. New York: Charles Scribner's Sons, 1894: 257.

4 Kauffmann F, Becklake MR. Maladies obstructives pulmonaires: un paradigme de la complexité des différences de santé entre hommes et femmes. In: SaurelCubizolles MJ, Blondell B, eds.La santé des femmes. Paris: Flammarion, Medecine et Sciences, 1996: 209-33.

5 Kauffmann F, Becklake MR. In: Annesi-Maesano I, Gulsvik A, Viegi G, eds. Sex and gender. European Respiratory Monographs. Respiratory Epidemiology 1999 (in press)

6 Sparrow D, Weiss ST. Background. In: Weiss S, Sparrow D, eds. Airway responsiveness and atopy in the development of eds. Airway responsiveness and atopy in the development
chronic lung disease. New York: Raven Press, 1989: 1-19.

7 Manfreda J, Mao Y, Litven W. Morbidity and mortality from chronic obstructive pulmonary disease. Am Rev Respir Dis 1989;140:S19-26.

8 Brody JS, Thurlbeck WM. Development, growth and ageing of the lung. In: Fishman AP, Macklem PT, Mead J, eds. Handbook of physiology. A critical comprehensive presentation of physiologic knowledge and concepts. Section 3. The respiratory system: Vol III. Mechanics of breathing, Part 1. American Physiological Society; 1986: 355-86.

9 Similowski T, Doré M-F, Marazzini L, et al. Expiration forcée: quelques concepts actuels, 50 ans après Robert Tiffeneau. Rev Mal Respir 1998;14:431.

10 Grisso JA, Watkins K. A framework for a women's health research agenda. F Women's Health 1992;1:177-83.

11 Bone CR, Higgins MW, Hurd SS, et al. Research needs and opportunities related to respiratory health of women. Am Rev Respir Dis 1992;146:528-35.

12 Healy B. The Yentl syndrome. N Engl f Med 1991;325:274

13 Last JM. A dictionary of epidemiology. 3rd ed. New York: Oxford University Press, 1995: ?-180.

4 Becklake MR, Ernst P. Asthma: environmental factors. Lan cet 1997;350(Suppl 2):10-3.

15 Thurlbeck WM. Postnatal human lung growth. Thorax 1982;37:564-71

16 Zapletal A, Motoyama EK, Van De Woestijne KP, et al. Maximum expiratory flow-volume curves and airway conductance in children and adolescents. F Appl Physiol 1969; 26:308-16.

17 Mead J. Dysanapsis in normal lungs assessed by the Mead J. Dysanapsis in normal lungs assessed by the relationship between maximal flow, static recoil,

18 Mead J, Turner JM, Macklem PT, et al. Significance of the relationship between lung recoil and maximum expiratory flow. F Appl Physiol 1967;22:95-108. 
19 Green M, Mead J, Turner JM. Variability of maximum expiratory flow-volume curves. F Appl Physiol 1974;37:6774.

20 Quanjer PH, Borsboom GJ, Brunekreef B, et al. Spirometric reference values for white European children and adolescents: Polgar revisited. Pediatr Pulmonol 1995;19: 135-42.

21 Clausen JL, Coates AL, Quanjer PH. Measurement of lung volumes in humans: review and recommendations from an ATS/ERS workshop. Eur Respir f 1997;10:1205-6.

22 Stocks J, Quanjer PH. Reference values for residual volume, functional residual capacity and total lung capacity. ATS workshop on lung volume measurements. Official statement of the European Respiratory Society. Eur Respir $f$ ment of the Europ

23 American Thoracic Society. Lung function testing: selection of reference values and interpretative strategies. Am Rev Respir Dis 1991;144:1202-18.

24 Thurlbeck WM. Postnatal growth and development of the lung. Am Rev Respir Dis 1975;111:803-44.

25 Martin TR, Feldman HA, Fredberg JJ, et al. Relationship between maximal expiratory flows and lung volumes in growing humans. F Appl Physiol 1988;65:822-8.

26 Merkus PJFM, Borsboom GJJM, Van Pelt W, et al. Growth of airways and air spaces in teenagers is related to sex but not to symptoms. F Appl Physiol 1993;75:2045-53.

27 Tepper RS, Morgan WJ, Cota K, et al. Physiologic growth and development of the lung during the first year of life. $A m$ Rev Respir Dis 1986;134:513-9.

28 Hanrahan JP, Tager IB, Segal MR, et al. The effect of maternal smoking during pregnancy on early infant lung function. Am Rev Respir Dis 1992;145:1129-35.

29 Kauffmann F, Tager IB, Muñoz A, et al. Familial factors related to lung function in children aged 6-10 years. $A m \mathcal{F}$ Epidemiol 1989;129:1289-99.

30 Schwartz J, Katz SA, Fegley RW, et al. Sex and race differences in the development of lung function. Am Rev Respir Dis 1988;138:1415-21.

31 Schwartz JD, Katz SA, Fegley RW, et al. Analysis of spirometric data from a national sample of healthy 6- to 24-year-olds (NHANES II). Am Rev Respir Dis 1988;138: 1405-14.

32 Lebowitz M, Sherrill DL. The assessment and interpretation of spirometry during the transition from childhood to ation of spirometry during the transition from

33 Merkus PJFM, ten Have-Opbroek AAW, Quanjer PH Human lung growth: a review. Pediatr Pulmonol 1996;21 383-97.

34 Hepper PG, Shannon EA, Dornan JC. Sex differences in fetal mouth movements. Lancet 1997;350:1820.

35 Taussig LM, Cota K, Kaltenborn W. Different mechanical properties of the lung in boys and girls. Am Rev Respir Dis 1981;123:640-3.

36 Pagtakhan RD, Bjelland JC, Landau LI, et al. Sex differences in growth patterns of the airways and lung parenchyma in children. 7 Appl Physiol 1984;56:1204-10.

37 Tanner JM. Foetus into man. Physical growth from conception to maturity. Cambridge, Massachusetts: Harvard University Press, 1990:280.

38 Jeffrey PK. The development of large and small airways. Am F Respir Crit Care Med 1998;157:S174-80.

39 Doershuk CF, Fisher BJ, Matthews LW. Specific airway resistance from the perinatal period into adulthood. Alterations in childhood disease. Am Rev Respir Dis 1974;109: $452-7$.

40 Langston C, Kida K, Reed M, et al. Human lung growth in late gestation and in the neonate. Am Rev Respir Dis 1984 129:607-13.

41 Polgar G, Weng TR. The functional development of the respiratory system. From the period of gestation to adulthood. Am Rev Respir Dis 1979;120:625-95.

42 Wang X, Dockery DW, Wypij D, et al. Pulmonary function growth velocity in children 6 to 18 years of age. Am Rev Respir Dis 1993;148:1502-8.

43 Hibbert H, Lannigan A, Raven J, et al. Gender differences in lung growth. Pediatr Pulmonol 1995;19:129-34.

44 Torday JS, Nielsen HC. The sex difference in fetal lung surfactant production. Exp Lung Res 1987;12:1-19.

45 Boddy K, Dawes GS. Fetal breathing. Br Med Bull 1975;31: 3-7.

46 Fleisher B, Kulovich MV, Hallman M, et al. Lung profile: sex differences in normal pregnancy. Obstet Gynecol 1985;66:327.

47 Demissie K, Marcella SW, Breckenridge MB, et al. Maternal asthma and transient tachypnea of the newborn. Pediatrics 1998;102:84-90.

48 Tanner JM. Growth at adolescence. 2nd ed. Oxford: Blackwell Scientific Publications, 1962

49 Schrader PC, Quanjer PH, Olivier ICW. Respiratory muscle force and ventilatory function in adolescents. Eur Respir $\mathcal{F}$ 1988; 1:368-75

50 Hoffstein V. Relationship between lung volume, maxima expiratory flow, forced expiratory volume in one second, and tracheal area in normal men and women. Am Rev Respir Dis 1986;134:956-61.

51 Gibellino F, Osmanliev DP, Watson A, et al. Increase in tracheal size with age. Implications for maximal expiratory flow. Am Rev Respir Dis 1985;132:784-7.

52 Pepys J. Atopy. In: Gell PGH, Coumbs RRA, Lachman PJ, eds.Clinical aspects of immunology. Oxford: Blackwell Scieneds. Clinical aspects of immunology.
tific Publications, 1975: 877-902.

53 Blumenthal MN. Principles of genetics. In: Middelton EJ, Ellis EF, Yunginger JW, et al, eds. Allergy: principles and practice. St Louis: Mosby, 1998: 28-39.
54 Holgate ST. The cellular and mediator basis of asthma in relation to natural history. Lancet 1997;350(Suppl II): SII5-9.

55 Sapigni T, Biayati P, Simoni M, et al. The Po River Delta respiratory epidemiological survey: an analysis of factors related to level of total serum IgE. Eur Respir $\mathcal{f}$ 1998;11:278-83.

56 Gergen PJ, Turkeltaub PC, Kovar MG. The prevalence of allergic skin test reactivity to eight common aeroallergens in the U.S. population: results from the Second National Health and Nutrition Examination Survey. $\mathcal{F}$ Allergy Clin Immunol 1987;80:669-79.

57 Barbee RA, Kaltenborn W, Lebowitz MD, et al. Longitudinal changes in allergen skin test reactivity in a community population sample. $\mathcal{F}$ Allergy Clin Immunol 1987;79:16-24.

58 Cline MG, Burrows B. Distribution of allergy in a population sample residing in Tucson, Arizona. Thorax 1989;44:425-31.

59 Sears MR, Burrows B, Flannery EM, et al. Atopy in childhood. I. Gender and allergen related risks for development of hay fever and asthma. Clin Exp Allergy 1993;23: 941-8.

60 Sears MR, Burrows B, Herbison GP, et al. Atopy in childhood. II. Relationship to airway responsiveness, hay fever and asthma. Clin Exp Allergy 1993;23:949-56.

61 Sears MR, Burrows B, Herbison GP, et al. Atopy in childhood. III. Relationship with pulmonary function and airway responsiveness. Clin Exp Allergy 1993;23:957-63.

62 Burney P, Malmberg E, Chinn S, et al. The distribution of total and specific serum IgE in the European Community Respiratory Health Survey. F Allergy Clin Immunol 1997;99: 314-22.

63 Burney P, Chinn S, Jarvis D, et al. Variations in the prevalence of respiratory symptoms, self-reported asthma attacks, and use of asthma medication in the European Community Respiratory Health Survey. Eur Respir f 1996; 9:687-95.

64 Asher MI, Keil U, Anderson HR, et al. International study of asthma and allergies in childhood (ISAAC): rationale and methods. Eur Respir f 1995;8:483-91.

65 Chan-Yeung M, Vedal S, Lam S, et al. Immediate skin reactivity and its relationship to age, sex, smoking, and occupational exposure. Arch Environ Health 1985;40:53-7.

66 Bousquet J, Coulomb Y, Arrendal H, et al. Total serum IgE concentrations in adolescents and adults using the Phadebas IgE PRIST technique. Allergy 1982;37:397-406.

67 Jarvis D, Luczynska C, Chinn S, et al. The association of age, gender and smoking with total IgE and specific IgE. Clin Exp Allergy 1995;25:1083-91.

68 Dimich-Ward H, Manfreda J, Sears MR, et al. Determinants of total IgE levels based on a Canadian prevalence study. Am 7 Respir Crit Care Med 1997;155:A80.

69 Zetterstrom O, Johansson SGO. IgE concentrations measured by PRIST in serum of healthy adults and in patients with respiratory allergy. Allergy 1981;36:537-47.

70 Villar T, Holgate ST. IgE, smoking and lung function. Clin Exp Allergy 1994;24:508-10.

71 Omenaas E, Bakke P, Elsayed S, et al. Total and specific serum IgE levels in adults: relationship to sex, age and serum IgE levels in adults: relationship to sex, age and
environmental factors. Clin Exp Allergy 1993;24:530-9.

72 Burrows B, Barbee RA, Cline MG, et al. Characteristics of asthma among elderly adults in a sample of the genera population. Chest 1991;100:935-42.

73 Prescott SL, Mccaubas C, Smallacombe T, et al. Development of allergen-specific T-cell memory in atopic and normal children. Lancet 1999;353:196-200.

74 Biorksten B. Allergy priming early in life. Lancet 1999;353: $167-8$.

75 Downing ET, Braman SS, Fox MJ, et al. Factitious asthma. Physiological approach to diagnosis. $\mathscr{F} A M A$ 1982;248: 2878-81.

76 Wegmann T, Lin H, Gulbert L, et al. Bidirectional cytokine interactions in the maternal-fetal relationship: is successful pregnancy a Th2 phenomenon? Immunol Today 1993;14: 353-6.

77 Holt PG, Sly PD. Allergic respiratory disease: strategic targets for primary prevention during childhood. Thorax 1997;52:1-4.

78 Chan-Yeung M, Ferguson AC, Manfreda J, et al. Does exposure to house dust mite allergens occur in utero? $\mathrm{Am} \mathcal{F}$ Respir Crit Care Med 1997;155:A73.

79 Cookson WOCM, Moffatt MF. Asthma: an epidemic in the absence of infection. Science 1997;275:41-2.

80 Arshad SH, Matthews S, Gant C, et al. Effect of allergen avoidance on development of allergic disorders in infancy. Lancet 1992;339:1493-7.

81 Wist $\mathrm{M}$, Dold S. Is asthma an endocrine disease? Pediat Allergy Immunol 1997;8:200-4

82 Miles EA, Warner JA, Jones AC, et al. Peripheral blood mononuclear cell proliferation responses in the first year of life in babies born of allergic parents. Clin Exp Allergy 1996;26:780-8.

83 Shaheen SO, Aaby P, Hall AJ, et al. Measles and atopy in Guinea-Bissau. Lancet 1996;347:1792-6.

84 Holt P. Environmental factors and primary T-cell sensitisation to inhalant allergens in infancy: reappraisal of the role of infections and air pollution. Pediatr Allergy Immunol 1995;6:1-10.

85 Bjorksten B, Dumitrascu D, Foucard T, et al. Prevalence of childhood asthma, rhinitis and eczema in Scandinavia and Eastern Europe. Eur Respir f 1998;12:432-7.

86 Strachan DP. Allergy and family size: a riddle worth solving. Clin Exp Allergy 1997;27:235-6. 
87 Shirakawa T, Enomoto T, Shimazu SI, et al. The inverse association between tuberculin responses and atopic disorders. Science 1997;275:77-9.

88 von Mutius E, Martinez FD, Fritzsch C, et al. Skin test reactivity and number of siblings. BMf 1994;308:692-5

89 von Mutius E, Martinez FD, Fritzsch C, et al. Prevalence of asthma and atopy in two areas of west and east Germany. Am $\mathcal{F}$ Respir Crit Care Med 1994;149:358-64.

90 Platts-Mills TAE, Carter MC. Asthma and indoor exposure to allergens. N Engl F Med 1997;336:1382-4.

91 Johnson CC, Ownby DR, Peterson DL. Parental history of allergy and concentration of cord blood IgE. Clin Exp Allergy 1996;26:624-9.

92 Dempsey JA, Olson EBJ, Skatrud JB. Hormones and neurochemicals in the regulation of breathing. In: Cherniak NS, Widdicombe JG, eds. Handbook of physiology, Section 3: The respiratory system. Bethesda, Maryland: American Physiological Society, 1986: 181-222.

93 Smolensky MH, Reinberg A. Clinical chronobiology: relevance and applications to the practice of occupational medicine. Occupational Medicine: State of the Art Reviews 1990;5:239-72

94 Weinmann GG, Weidenbach-Gerbase M, Foster WM, et al. Evidence for ozone-induced small-airway dysfunction: lack of menstrual-cycle and gender effects. Am f Respir Crit Care Med 1995;152:988-96.

95 Kallenbach JM, Panz V, Girson MS, et al. The hormona response to exercise in asthma. Eur Respir 7 1990;3:171-5.

96 Bilancia R, Caputo G, Posca A, et al. CO diffusing capacity (DLCO) during menstruation cycle. Chest 1996; 110 (Suppl):61S.

97 Kharitonov SA, Logan-Sinclair RB, Busset CM, et al. Peak expiratory nitric oxide differences in men and women: relation to the menstrual cycle. Br Heart F 1994;72:243-5.

98 Weinmann GG, Zakur H, Fish JE. Absence of changes in airway responsiveness to methacholine during the menstrual cycle and the effect of oral contraceptives. F Allergy Clin Immunol 1987;79:634-8.

99 Juniper EF, Kline PA, Roberts RS, et al. Airway responsiveness to methacholine during the natural menstrual cycle and the effect of oral contraceptives. Am Rev Respir Dis 1987;135:1039-42.

100 Pauli BD, Reid RL, Munt PW, et al. Influence of the menstrual cycle on airway function in asthmatic and normal subjects. Am Rev Respir Dis 1989;140:358-62.

101 Alberts WM. Circa menstrual rhythmicity and asthma. Chest 1997;111:840-2.

102 Nagata K, Ishitobi K, Yamamoto Y, et al. Increased theophylline metabolism in the menstrual phase of healthy women. F Allergy Clin Immunol 1997;100:39-43.

103 Wheeldon NM, Newnham DM, Coutie WJ, et al. Influence of sex steroid hormones on the regulations of lymphocyte $\beta$ adrenoceptors during the menstrual cycle. $B$ f Clin Pharmacol 1994;37:583-8.

104 Tan KS, McFarlane LC, Lipworth BJ. Paradoxical down-regulation and desensitization of $\beta_{2}$ adrenoceptors by exogenous progesterone in female asthmatics. Chest 1997 ; 111:847-51.

105 Benyon HLC, Garnett ND, Barnes PJ. Severe premenstrual exacerbations of asthma: effects of intramuscular progesterone. Lancet 1988;332:370-2.

106 Perrin B, Bousquet J, Michel JF, et al. Severe premenstrual asthma. Lancet 1988;332:843-4.

107 Morris D. Severe premenstrual asthma. Lancet 1988;332: 844 .

108 Eliasson O, Scherzer HH, DeGraff ACJ. Morbidity in asthma in relation to the menstrual cycle. $\mathcal{F}$ Allergy Clin Immunol 1986;77:87-94.

109 Chandler MHH, Schuldheisz S, Phillips BA, et al. Premenstrual asthma: the effect of estrogen on symptoms, pulmonary function, and $\beta_{2}$ receptors. Pharmacotherapy
1997;17:224-34.

110 Edwards AL, Rose MS, Donovan LE, et al. Premenstrual exacerbation of life-threatening asthma: effect of gonadotropin releasing hormone analogue therapy. Can Respir ff 1996;3:203-6.

111 Skobeloff EM, Spivey WH, St Clair SS, et al. The influence of age and sex on asthma admissions. FAMA 1992;268 3437-40.

112 Zimmerman JL, Woodruff PG, Camargo CA Jr. Relationship of emergency department visits for acute asthma to menstrual cycle. Am f Respir Crit Care Med 1998;157: A160.

113 Foschino Barbaro MP, Saracino A, Piti A, et al. Influence of menstrual cycle on bronchial hyperresponsiveness. Eur Respir ₹ 1995;8(Suppl 19):104S.

114 Dauletbaev N, Garijatehkina L, Ametov A, et al. Pulmonary function and bronchial hyperresponsiveness in various phases of the menstrual cycle of asthmatic women. $A m \mathscr{F}$ Respir Crit Care Med 1996;155:A515.

115 Tan KS, McFarlane LC, Lipworth BJ. Modulation of airway reactivity and peak flow variability in asthmatics receiving the oral contraceptive pill. Am $\mathcal{F}$ Respir Crit Car Med 1997;155:1273-7.

116 Munakata M, Yamamoto S, Akiyama Y, et al. Female asthmatics have increased hypercapnic chemosensitivity during the luteal phase which is not associated with decline in airway function. Chest 1993;104:1718-22.

117 O'Connor BJ. Premenstrual asthma: still poorly understood. Thorax 1997;52:591-2

118 Kharitonov SA, O'Connor BJ, Evans DJ, et al. Allergeninduced late asthmatic reactions are associated with elevation of exhaled nitric oxide. Am $\mathcal{F}$ Respir Crit Care Med 1995;151:1894-9.
119 Tan KS, McFarlane LC, Coutie WJ, et al. Effects of exogenous female sex-steroid hormones on lymphocyte beta 2 -adrenoceptors in normal females. Br f Clin Pharmacol 1996;41:414-6.

120 Tan KS, McFarlane LC, Lipworth BJ. Loss of normal cyclical $\beta_{2}$ adrenoceptor regulation and increased premenstrual responsiveness to adenosine monophosphate in stable femal asthmatic patients. Thorax 1997;52:608-11.

121 Becklake MR. International Union Against Tuberculosis and Lung Disease (IUATLD): initiatives in nontuberculous lung disease. Tuberc Lung Dis 1995;76:493504 .

122 Odhiambo JA, Ng'ang'a LW, Mungai MW, et al. Urbanrural differences in questionnaire-derived markers of asthma in Kenyan school children. Eur Respir F 1998;12: 1105-12.

123 Ng'ang'a LW, Odhiambo JA, Mungai M, et al. Prevalence of exercise induced bronchospasm in Kenyan school children: an urban-rural comparison. Thorax 1998;53:91926 .

124 Yermaneberhan H, Bekele Z, Venn A, et al. Prevalence of wheeze and asthma and relation to atopy in urban and rural Ethiopia. Lancet 1997;350:85-90.

125 Bates DV. Respiratory function in disease. 3rd ed. Philadelphia: WB Saunders, 1998: 151.

126 Brancazio LR, Laifer SA, Schwartz T. Peak expiratory flow rate in normal pregnancy. Obstet Gynecol 1997;89:383-6.

127 Juniper EF, Daniel EE, Roberts RS, et al. Improvement in airway responsiveness and asthma severity during
pregnancy: a prospective study. Am Rev Respir Dis pregnancy: a prost

128 Stenius-Aarniala BSM, Hedman J, Teramo KA. Acute asthma during pregnancy. Thorax 1996;51:411-4.

129 Shanies HM, Venkataraman MT, Peter T. Reversal of intractable acute severe asthma by first-trimester termination of pregnancy. F Asthma 1997;34:169-72.

130 Schatz M, Harden K, Forsythe A, et al. The course of asthma during pregnancy, post partum, and with successive pregnancies: a prospective analysis. F Allergy Clin Immunol 1988;81:509-17.

131 Stenius-Aarniala B, Piirila P, Teramo K. Asthma and pregnancy: a prospective study of 198 pregnancies. Thorax 1988;43:12-8.

132 Beecroft N, Cochrane GM, Milburn J. Effect of sex of foetus on asthma during pregnancy: blind prospective study. BMF 1998;317:856-7.

133 Troisi RJ, Speizer FE, Willett WC, et al. Menopause, postmenopausal estrogen preparations, and the risk of adultonset asthma. Am ₹ Respir Crit Care Med 1995;152:1183-8.

134 Lieberman D, Kopernik G, Porath A, et al. Sub-clinical worsening of bronchial asthma during estrogen replacement therapy in asthmatic post-menopausal women. Matument therapy in asthmat
ritas 1995;21:153-7.

135 Masi MA, Hanley JA, Ernst P, et al. Environmental exposure to tobacco smoke and lung function in young adults. Am Rev Respir Dis 1988;138:296-9.

136 Gold DR, Wang X, Wypij D, et al. Effects of cigarette smoking on lung function in adolescent boys and girls. $N$ Engl F Med 1996;335:931-7.

137 Comstock GW, Meyer MB, Helsing KJ, et al. Respiratory effects of household exposures to tobacco smoke and gas cooking. Am Rev Respir Dis 1981;124:143-8.

138 Jarvis D, Chinn S, Luczynska C. Association of respiratory symptoms and lung function in young adults with use of domestic gas appliances. Lancet 1996;347:426-31.

139 Brauer M, Kennedy SM. Gas stoves and respiratory health. Lancet 1996;347:412

140 Chan-Yeung M, Malo J-L. Occupational asthma. N Engl $\mathcal{F}$ Med 1995;333:107-12.

141 Fuhlbrigge A, Weiss S. Domestic gas appliances and lung disease. Lancet 1996;347:426-31.

142 Dales RE, Spitzer WO, Schechter MT, et al. The influence of psychological status on respiratory symptom reporting. Am Rev Respir Dis 1989;139:1459-63.

143 Hsairi M, Kauffmann F, Chavance M, et al Personal factors related to the perception of occupational exposure: an application of a job exposure matrix. Int $f$ Epidemio an application of

144 Jones PW, Baveystock CM, Littlejohns P. Relationships between general health measured with the sickness impact profile and respiratory symptoms, physiological measures, and mood in patients with chronic airflow limitations. $A m$ Rev Respir Dis 1989;140:1538-43.

145 Chen Y, Horne SL, Dosman JA. Increased susceptibility to lung dysfunction in female smokers. Am Rev Respir Dis 1991;143:1224-30.

146 Forastiere F, Agabiti N, Corbo GM, et al. Passive smoking as a determinant of bronchial responsiveness in children. Am 7 Respir Crit Care Med 1994;149:365-70.

$147 \mathrm{Xu}$ X, Weiss ST, Rijcken B, et al. Smoking changes in smoking habits, and rate of decline in $\mathrm{FEV}_{1}$ : new insight into gender differences. Eur Respir $\mathcal{F}$ 1994;7:1056-61.

148 Xu X, Wang L. Gender difference in smoking effects on adult pulmonary function. Eur Respir f 1994;7:477-83.

149 Prescott E, Bjerg AM, Andersen PK, et al. Gender difference in smoking effects on lung function and risk of hospitalization for COPD: results from a Danish longitudinal population study. Eur Respir f 1997;10:822-7.

$150 \mathrm{Xu}$ X, Weiss ST, Rijcken B, et al. Association of smoking and changes in smoking habits with rate of decline in $\mathrm{FEV}_{1}$ : new insight into gender differences. Eur Respir f 1994;7: 
151 Becklake MR, Lalloo U. The "healthy smoker": a phenomenon of health selection. Respiration 1990;57:137 44.

152 Dodge R, Cline MG, Burrows B. Comparisons of asthma emphysema, and chronic bronchitis diagnoses in a genera population sample. Am Rev Respir Dis 1986;133:981-6.

153 Schwab RJ. Sex differences and sleep apnea. Thorax 1999; 54:284-5.

154 Guslvik A. Prevalence of respiratory symptoms in the city of Oslo. Scand F Respir Dis 1979;60:275-85.

155 Krzyzanowski M, Lebowitz MD. Changes in chronic respiratory symptoms in two populations of adults studied longitudinally over 13 years. Eur Respir f 1992;5:12-20.

156 Krzyzanowski M, Jedrychowski W, Wysocki M. Factors associated with the change in ventilatory function and the development of chronic obstructive pulmonary disease in a 13-year follow-up of the Cracow study. Am Rev Respir Dis 13-year follow-up

157 Viegi G, Prediletto R, Paoletti P, et al. Respiratory effects of occupational exposure in a general population sample in north Italy. Am Rev Respir Dis 1991;143:510-5.

158 Thom TJ. International comparisons in COPD mortality. Am Rev Respir Dis 1989;140:S27-34.

159 Vollmer WM, Buist AS, Osborne ML. Twenty year trends in hospital discharges for asthma among members of health maintenance organization. I Clin Epidemiol 1992;45:1-8.

160 PAARC.Groupe coopératif. Pollution atmosphérique et affections respiratoires chroniques ou à répétition. I. Méthodes et matériel. Bull Eur Physiopathol Respir 1982;18:87odes
99.

161 Krzyzanowski M, Kauffmann F. The relation of respiratory symptoms and ventilatory function to moderate occupational exposure in a general population. Int $\mathcal{F}$ Epidemio 1988; 17:397-406.

162 Jones P, Quirk F, Baveystock C, et al. A self-complete measure of health status for chronic airflow limitation. The St George's Respiratory Questionnaire. Am Rev Respir Dis 1992;145:1321-7

163 Diepinigaitis PV, Khalid R. The influence of gender on cough reflex sensitivity. Chest 1998;113:1319-21.

164 Wilkins K, Mao Y. Trends in rates of admission to hospital and death from asthma among children and young adults in Canada during the 1980s. Can Med Assoc F 1993;148: 185-90.

165 Mao Y, Semenciw R, Morrison H, et al. Increased rates of illness and death from asthma in Canada. Can Med Assoc $\mathcal{F}$ 1987; 137:620-4.

166 Balzan MV. Age and sex distribution of adult asthma admission: a study of the five-year cumulative prevalence. Maltese Med F 1997;9:28-3

167 Vollmer WM, Osborne ML, Buist AS. Twenty-year trends in the prevalence of asthma and chronic airflow obstruction in an HMO. Am F Respir Crit Care Med 1998;157:1079-84.

168 Mannino DM, Homa DM, Pertowski CA, et al. Surveillance for asthma: United States, 1960-1995. Surveillance summaries, 24 April 1998. MMWR 1998;47:1-26.

169 Beasley R, Keil U, von Mutius E, et al. Worldwide variation in prevalence of symptoms of asthma, allergic rhinoconjunctivitis, and atopic eczema: ISAAC Lancet 1998:351: 1225-32.

170 SIDRIA (Italian Studies on Respiratory Disorders in Childhood and the Environment). Asthma and respiratory symptoms in 6-7 year old Italian children: gender, urbanisymptoms in 6-7 year old Italian children: gender, urbanization and

171 Manfreda J, Yeung M, Dimich-Ward H, et al. Prevalence of asthma-like symptoms in four Canadian cities. Am $\mathcal{F}$ Respir Crit Care Med 1995;151:A29.

172 Sunyer J, Anto JM, Kogevinas M, et al. Risk factors for asthma in young adults. Eur Respir f 1997;10:2490-4.

173 Kollef MH, O’Brien JD, Silver P. The impact of gender on outcome from mechanical ventilation. Chest 1997;111 434-41.

174 Jarvholm B, Brisman J, Toren K. The association between epidemiological measures of the occurrence of asthma. Int f Tuberc Lung Dis 1998;2:1029-36.

175 Fletcher CM, Pride NB. Definitions of emphysema, chronic bronchitis, asthma, and airflow obstruction: 25 years on from the Ciba symposium. Thorax 1984;39:81-5.

176 Postma DS, Siafakas NM. Management of chronic Postma DS, Siafakas NM. Management of chro
obstructive lung disease. Eur Respir Monogr 1998;3:2-6.

177 Anthonisen NR. Lung Health Study. Am Rev Respir Dis 1989;140:871-2.

178 National Institutes of Health. Global strategy for asthma management and prevention. Publication no. 95-3659. NHLBI/WHO Workshop Report. 1995: 1.

179 Pauwels RA, Löfdahl C-G, Pride NB, et al. Eeropean respiratory society study on chronic obstructive pulmonary disease (EUROSCOP): hypothesis and design. Eur Respir 7 1992;5:1254-61.

180 Thurlbeck WM, Muller NL. Emphysema: definition, imaging, and quantification. $A \mathscr{F} R$ 1994;163:1017-25.

181 Sluiter HJ, Koëter GH, de Monchy JGR, et al. The Dutch hypothesis (chronic non-specific lung disease) revisited. Eur Respir f 1991;4:479-89.

182 Woolcock A. Asthma. In: Murray JF, Nadel JA, eds. Textbook of respiratory medicine. Philadelphia: WB Saunders, 1994: 1288-330.
183 Paoletti P, Viegi G, Carrozzi L. Bronchial hyperresponsiveness, genetic predisposition and environmental factors: the importance of epidemiological research. Eur Respir F 1992; 5:910-2

184 Snider GL. What's in a name? Names, definitions, descriptions, and diagnostic criteria of diseases, with emphasis on chronic obstructive pulmonary disease. Respiration 1995; 62:297-301.

185 American Thoracic Society. Standards for the diagnosis and care of patients with chronic obstructive pulmonary and care of patients with chronic obstructive pulmonar
disease. Am f Respir Crit Care Med 1995;152:s77-120.

186 Stacenko AA, Hutchison AA. Phascinating physiology. Am Rev Respir Dis 1991;144:1008-11.

187 Cockroft DW, Hargreave FE. Airway hyperresponsiveness. Relevance of random population data to clinical usefulness. Am Rev Respir Dis 1990;142:497-500.

188 Stick SM, Turnbull S, Chua HL, et al. Bronchial responsiveness to histamine in infants and older children. Am Rev Respir Dis 1990;142:1143-6.

189 Ng'ang'a LW. The epidemiology of childhood asthma in Kenya 1996. PhD thesis. McGill University.

190 Zhong NS, Chen RC, O-Yang M, et al. Bronchial hyperresponsiveness in young students of southern China: relation to respiratory symptoms, diagnosed asthma, and risk factors. Thorax 1990;45:860-5.

191 Bakke PS, Baste V, Gulsvik A. Bronchial responsiveness in a Norwegian community. Am Rev Respir Dis 1991;143: 317-32.

192 Tashkin DP, Altose MD, Bleecker ER, et al. The lung health study: airway responsiveness to inhaled methacholine in smokers with mild to moderate airflow limitation. Am Rev Respir Dis 1992;145:301-10.

193 Peat JK, Salome CM, Woolcock AJ. Factors associated with bronchial hyperresponsiveness in Australian adults and children. Eur Respir F 1992;5:921-9.

194 Ulrik CS, Backer V, Dirksen A. A 10 year follow up of 180 adults with bronchial asthma: factors important for the decline in lung function. Thorax 1992;47:14-8.

195 Rijcken B, Schouten JP, Mensinga TT, et al. Factors associated with bronchial responsiveness to histamine in a population sample of adults. Am Rev Respir Dis 1993;147: 1447-53.

196 Le Souëf PN, Sears MR, Sherrill D. The effect of size and age of subject on airway responsiveness in children. $A m$ Respir Crit Care Med 1995;152:576-9.

197 Chinn S, Burney P, Jarvis D, et al. Variation in bronchial responsiveness in the European Community Respiratory Health Survey (ECRHS). Eur Respir f 1997;10:2495-501.

198 Leynaert B, Bousquet J, Henry C, et al. Is bronchial hyperresponsiveness more frequent in women than in men? $A m$ f Respir Crit Care Med 1997;156:1413-20.

199 Kanner RE, Connett JE, Altose MD, et al. Gender difference in airway hyperresponsiveness in smokers with mild COPD. Am $\mathcal{F}$ Respir Crit Care Med 1994;150:956-61.

200 Peat JK, Salome CM, Xuan W. On adjusting measurements of airway responsiveness for lung size and airway caliber. Am 7 Respir Crit Care Med 1996;154:870-5.

201 Paoletti P, Carrozzi L, Viegi G, et al. Distribution of bronchial responsiveness in a general population: effects of sex, age, smoking, and level of pulmonary function. Am $\mathcal{F}$ Respi Crit Care Med 1995;151:1770-7.

202 Trigg CJ, Bennett JB, Tooley M, et al. A general practice based survey of bronchial hyperresponsiveness and its relation to symptoms, sex, age, atopy, and smoking. Thorax 1990;45:866-72

203 Taussig LM, Wright AL, Morgan WJ, et al. The Tucson children's respiratory study. I. Design and implementation of a prospective study of acute and chronic respiratory illness in children. Am ₹ Epidemiol 1989;129:1219-31.

204 Martinez FD, Wright AL, Taussig LM, et al. Asthma and wheezing in the first six years of life. $N$ Engl $7 \mathrm{Med}$ wheezing in the

205 Redline S, Gold D. Challenges in interpreting gender differences in asthma. Am $\mathcal{F}$ Respir Crit Care Med 1994;150 1219-21.

206 Weiss ST, Gold D. Gender differences in asthma. Pediatr Pulmonol 1995;19:153-5.

207 Feinleib M, Rosenberg HM, Collins JG, et al. Trends in COPD morbidity and mortality in the United States. $\mathrm{Am}$ Rev Respir Dis 1989;140:S9-18.

208 Becklake MR. Occupational exposures: evidence for a causal association with chronic obstructive pulmonary disease. Am Rev Respir Dis 1989;140(Suppl):S85-91.

209 Becklake MR. The workrelatedness of airways dysfunction. In: US Department of Health and Human Services, Public Health Service, Centers for Disease Control, National Institute for Occupational Health, eds. Proceeedings of the 9th International Symposium on Epidemiology in Occupational Health. Cincinnati, Ohio: DHHS (NIOSH), 1994: 1-28.

210 Quanjer PH, Stocks J, Polgar G, et al. Compilation of reference values for lung function measurements in children. Eur Respir ₹ 1989;2(Suppl 4):184-261s.

211 Becklake MR, White N. Sources of variation in spirometric measurements. Occup Med 1993;8:241-64. 